\title{
Insights into DNA Platination within Unusual Structural Settings
}

\author{
Stephanie Harvie, Owen Wilson, and John A. Parkinson \\ WestCHEM Department of Pure and Applied Chemistry, Thomas Graham Building, University of Strathclyde, \\ 295 Cathedral Street, Glasgow G1 1XL, UK \\ Correspondence should be addressed to John A. Parkinson, john.parkinson@strath.ac.uk
}

Received 15 September 2011; Accepted 24 November 2011

Academic Editor: Stephen Ralph

Copyright ( 2011 Stephanie Harvie et al. This is an open access article distributed under the Creative Commons Attribution License, which permits unrestricted use, distribution, and reproduction in any medium, provided the original work is properly cited.

\begin{abstract}
2D $\left[{ }^{1} \mathrm{H},{ }^{15} \mathrm{~N}\right]$ HSQC NMR spectroscopy has been used to monitor reaction and product formation between $\left.\left[\mathrm{Pt}^{15}{ }^{15} \mathrm{NH}_{3}\right)_{2} \mathrm{I}_{2}\right]$ and nucleic acids possessing irregular topologies and containing site-specific phosphorothioate substitution in the phosphodiester backbone. Comparison of the reaction profiles of dimer nucleic acids with and without phosphorothioate substitution is made with their short nucleic acid counterparts containing the key dimer components. Whereas $\mathrm{d}(\mathrm{GpA})$ is relatively unreactive towards $\left[\mathrm{Pt}\left({ }^{15} \mathrm{NH}_{3}\right)_{2} \mathrm{I}_{2}\right]$, NMR evidence suggests that the tandem sheared mismatch duplex $\mathrm{d}\left(\mathrm{GCG}^{3} \mathrm{pAGC}\right)_{2}$ reacts to form the head-to-tail interstrand G3-N7-Pt-G3-N7 cross-link. The equivalent phosphorothioate $R, S-\mathrm{d}(\mathrm{GsA})$ reacts to form a monoiodo,

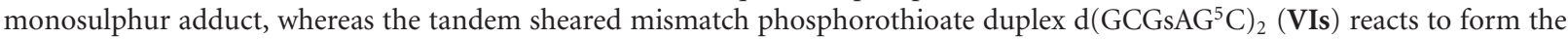
unusual intrastrand macrochelate $\left[\mathrm{Pt}\left({ }^{15} \mathrm{NH}_{3}\right)_{2}\left\{\mathrm{~d}\left(\mathrm{VIs}-\mathrm{G}^{5}-\mathrm{N} 7\right)\right\}, S\right]^{2+}$, in which platinum is attached at both sulphur and $\mathrm{G}^{5}-\mathrm{N} 7$. Experimental evidence supports the formation of a stabilized mismatch duplex in which platinum is attached to two nitrogen centres in the sequence d(CGCGpTGCG) in contrast to $R, S$-d(CGCGsT ${ }^{5}$ GCG) for which NMR evidence supports macrochelatestabilized hairpin loop formation cross-linked at both phosphorothioate sulphur and $\mathrm{T}^{5}-\mathrm{N} 3$.
\end{abstract}

\section{Introduction}

The concept of targeted approaches to cancer chemotherapy is increasingly delivering candidate innovations with real potential for application in the clinic [1-3]. Distress to patients caused through the toxic side-effects brought about by systemic delivery of active drugs could be reduced or perhaps eliminated in instances where a cancer is localized, and an inactive prodrug could be delivered and activated solely at the target site, either through reduction within the cell [4] or by means of some external stimulation mechanism $[5,6]$. The aim of such localization together with the specific targeting of genes associated with cell immortalization is of real value in the development of new candidate targeting drugs. The branch of anticancer drug therapy involving metallodrugs, especially those based on the platinum compound cisplatin (cis-diamminedichloroplatinum (II)) has seen particular success in the treatment of testicular, bladder, lung, stomach, and ovarian cancers [7] combined with the development of a wide number of analogues developed in attempts to over-come drug resistance [8]. The concept of directing platinum to a specific site involving sulphur was previously explored by examining the reactivity of phosphorothioatecontaining monomer nucleotides in order to investigate their potential use in aiding cross-link formation within oligonucleotides (ODNs) and between oligonucleotides and proteins [9]. Sulphur is highly reactive towards platinum (II), and where it is available and abundant in biological systems in the form of glutathione (GSH) and free sulphur-containing proteins, a number of different platinum adducts readily form [10-13]. A concept proposed previously combined the idea of gene targeting in an antisense fashion using phosphorothioate-labelled oligonucleotides together with delivery of $\mathrm{Pt}^{\mathrm{II}}$ drugs with known clinical success [14], which are also highly reactive towards sulphur targets. Such an approach would enable gene targeting with localized therapy, provided the initial drug delivery could be prosecuted with the drug in a dormant, inactive (i.e., prodrug) state as proposed with activation taking place by means of an external inducing agent [15-17]. 
In order to begin to explore such a potential therapeutic approach, the fundamental characteristics of the associated chemistry needs to be first understood. Previously, the model mononucleotide guanosine- $5^{\prime}-O$-(2-thiodiphosphate) $[\mathrm{GDP}-\beta-\mathrm{S}]$ was chosen as a starting point to explore the reaction profiles and products of phosphorothioatelabelled oligonucleotides with $\mathrm{Pt}^{\mathrm{II}}$ drugs using ${ }^{15} \mathrm{~N}$-labelled cis- $\left[\mathrm{PtI}_{2}\left({ }^{15} \mathrm{NH}_{3}\right)_{2}\right]$, the iodide analogue of cisplatin. The presence of a ${ }^{15} \mathrm{~N}$ spin-label within the inorganic complex allows reactions to be elegantly monitored by means of $2 \mathrm{D}$ $\left[{ }^{1} \mathrm{H},{ }^{15} \mathrm{~N}\right]$ HSQC NMR spectroscopy according to tried and tested principles. Formerly, it was shown that macrochelate formation occurred in the form of cis- $\left[\mathrm{Pt}\left(\mathrm{NH}_{3}\right)_{2}(\mathrm{GDP}-\beta\right.$ $\mathrm{S})-N 7, S]$ in which $\mathrm{Pt}$ was bound to the $N 7$ and $S$ centres of a macrochelate [14]. Reactions with model ODNs were also monitored in a similar way, and speculation was made concerning the nature of the products formed. The commercially available model phosphorothioate (sulphur at the $\beta$-position on a diphosphate rather than at the $\alpha$-position on a monophosphate) and the makeup of the manufactured phosphorothioate-labelled ODNs (e.g., self-complementary 5'-TATGsGCCATA-3' for which, in the duplex form, there are potentially three different duplex structures; namely, $R, R$, $R, S=S, R$ and $S, S$ diastereoisomers) created an unnatural scenario in the former case and an excessive level of complexity in the latter case, which made interpretation of the experimental results somewhat difficult and occasionally inconclusive [14].

In an attempt to circumvent these issues, the work reported here has focussed as far as possible on monitoring reactions between cis- $\left[\mathrm{Pt}\left({ }^{15} \mathrm{NH}_{3}\right)_{2} \mathrm{I}_{2}\right]$ and model ODNs with one reacting phosphorothioate centre. Since these were supplied from a commercial source, mixtures of $R$ and $S$ forms were also used but with the level of complexity reduced by minimizing the number of available reaction sites. In the process of considering candidate ODN targets, the opportunity arose to also explore the reaction of cis$\left[\mathrm{Pt}\left({ }^{15} \mathrm{NH}_{3}\right)_{2} \mathrm{I}_{2}\right]$ with stable, alternative DNA geometries. In this work, we report the results of monitoring by NMR spectroscopy the reactions between cis- $\left[\mathrm{Pt}\left({ }^{15} \mathrm{NH}_{3}\right)_{2} \mathrm{I}_{2}\right], \mathbf{I}$, and the model dimers $5^{\prime}-\mathrm{d}(\mathrm{GpG})-3^{\prime}(\mathbf{I I}),(R, S)-5^{\prime}-\mathrm{d}(\mathrm{GsG})-3^{\prime}$ (IIs), $5^{\prime}-\mathrm{d}(\mathrm{GpA})-3^{\prime}$ (III), (R,S)-5'-d(GsA)-3' (IIIs), $5^{\prime}-\mathrm{d}(\mathrm{GpT})-3^{\prime}$ (IV), and $(R, S)-5^{\prime}-\mathrm{d}(\mathrm{GsT})-3^{\prime}$ (IVs). These reactions were monitored together with those associated with the single strand ODN $5^{\prime}$-d(ATATGpGTATA)-3' (V), the matched 10mer duplex ODN associated with the single occurrence of $\mathrm{d}(\mathrm{Gs} G)$ in the context $(R, S)-5^{\prime}-\mathrm{d}($ ATATGsGTATA $)-3^{\prime} \cdot 5^{\prime}$ d(TATACCATAT) $-3^{\prime}$ (Vs), and with mismatched ODNs $5^{\prime}$ $\mathrm{d}\left(\mathrm{GCG}\right.$ AGC)-3' (VI), (R,S)-5' -d(GCGsAGC)-3' (VIs), $5^{\prime}$ -

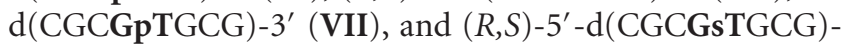
$3^{\prime}$ (VIIs). The results are discussed in the context of exploring these reactions from the starting point of photoactivatable $\mathrm{Pt}^{\mathrm{IV}}$ species.

\section{Experimental}

2.1. Materials. Potassium tetrachloroplatinate $\left(\mathrm{K}_{2} \mathrm{PtCl}_{4}\right)$ and deuterated water $\left(\mathrm{D}_{2} \mathrm{O}\right)$ were obtained from Sigma-Aldrich (99.9\% and $99.8 \%$, lot numbers $06208 \mathrm{AJ}$ and $03033 \mathrm{HC}$, resp.). ${ }^{15} \mathrm{~N}$-labelled ammonium chloride $\left({ }^{15} \mathrm{NH}_{4} \mathrm{Cl}\right)$ was purchased from Isotec (98+\% purity, lot number CX0410). Lithium perchlorate $\left(\mathrm{LiClO}_{4}\right)$ was supplied by Alfa Aesar (98\% purity, lot number FA032845). All oligonucleotides (ODNs) were purchased from Alpha DNA, Montreal, QC, Canada and produced on a $15 \mu \mathrm{mol}$ scale. ODNs were supplied as dry lyophilized powders having been purified by HPLC. ODNs were dissolved in $\mathrm{H}_{2} \mathrm{O}$ and freeze-dried overnight to remove volatile materials left over from the solid phase synthesis.

2.2. Compound Preparation. cis- $\left[\mathrm{Pt}\left({ }^{15} \mathrm{NH}_{3}\right)_{2} \mathrm{I}_{2}\right]$ was prepared from $\mathrm{K}_{2} \mathrm{PtCl}_{4}(0.25 \mathrm{~g}, 0.6 \mathrm{mmol})$ and $\mathrm{KI}(0.5 \mathrm{~g}$, $3 \mathrm{mmol})$, which were mixed in water $(7.5 \mathrm{~mL})$ and stirred for several minutes at $55^{\circ} \mathrm{C}$ when the solution turned from red to a red/brown colour. In a separate operation, ${ }^{15} \mathrm{NH}_{4} \mathrm{Cl}$ $(0.17 \mathrm{~g}, 3 \mathrm{mmol})$ was dissolved in deionised water $(2.5 \mathrm{~mL})$, and the solution was then neutralised with $\mathrm{KOH}(0.16 \mathrm{~g}$, $3 \mathrm{mmol}$ ). The resulting solution was added with stirring to the platinum-containing solution. Heating was prolonged for a further 15 minutes during which time a yellow precipitate separated out. The solid was collected on a sinter funnel and washed with ice cold water and ethanol. (Yield $77.5 \%)$. Product formation was verified by $2 \mathrm{D}\left[{ }^{1} \mathrm{H},{ }^{15} \mathrm{~N}\right]$ HSQC NMR spectroscopy which showed a characteristic ${ }^{15} \mathrm{~N}-{ }^{1} \mathrm{H}$ cross-peak at $\delta\left({ }^{15} \mathrm{~N} /{ }^{1} \mathrm{H}\right)=-55.12 / 3.99$ together with its ${ }^{195} \mathrm{Pt}$ satellite peaks. Chemical shift values obtained for the main peak agreed with those of an external standard of ${ }^{15} \mathrm{NH}_{4} \mathrm{Cl}$ quoted in the literature.

2.3. NMR Sample Preparation. NMR samples were prepared and admitted to Wilmad 535-PP-7 precision $5 \mathrm{~mm} \varnothing \mathrm{NMR}$ tubes in preparation for data collection. Typically reactions of ODNs with cis- $\left[\mathrm{Pt}\left({ }^{15} \mathrm{NH}_{3}\right)_{2} \mathrm{I}_{2}\right]$ were monitored by preparation of a solution of nucleic acid in $90 \% \mathrm{H}_{2} \mathrm{O} / 10 \% \mathrm{D}_{2} \mathrm{O}$ $(550 \mu \mathrm{L}, 2 \mathrm{mM})$ followed by the addition of an equimolar quantity of cis- $\left[\mathrm{Pt}\left({ }^{15} \mathrm{NH}_{3}\right)_{2} \mathrm{I}_{2}\right]$. Samples were quickly mixed by shaking and then admitted to the NMR magnet. Locking and shimming were controlled automatically and data acquisition was started as soon as possible after magnetic field stabilization. Reactions were monitored continuously without removal of the sample from the magnet.

2.4. NMR Spectroscopy. NMR data were acquired at a magnetic field strength of 14.1 Tesla using a Bruker Avance III NMR spectrometer operating at an ${ }^{1} \mathrm{H}$ resonance frequency of $600.13 \mathrm{MHz}$ using TopSpin version 2.1 (Bruker Biospin, Karlsruhe, Germany) on an HP XW3300 workstation running under Windows XP. Typically all NMR spectra were acquired on the prepared samples using a $5 \mathrm{~mm}$ triple resonance TBI probehead equipped with an actively shielded $z$ pulsed field gradient coil.

1D ${ }^{1} \mathrm{H}$ NMR data acquisitions were carried out using a double-pulsed field gradient spin echo procedure [18] to eliminate the solvent resonance. Data were typically acquired with 128 transients over a frequency width of $12 \mathrm{kHz}$ centred at $4.694 \mathrm{ppm}$ and acquired into $16 \mathrm{~K}$ data points in an acquisition time of $0.66 \mathrm{~s}$ using a recovery delay of 2 seconds. Preacquisition delays were set to values of typically 1000 , 
5000, and 15000 seconds in order to generate suitable delays for monitoring reaction processes.

2D $\left[{ }^{1} \mathrm{H},{ }^{15} \mathrm{~N}\right]$ HSQC NMR spectra were acquired using the Bruker pulse program hsqcetf3gpsi with 32 transients for each of 128 free induction decays using an echo/antiecho mode of acquisition over a $\omega_{2}$ frequency width of $10 \mathrm{ppm}$ centred at $4.69 \mathrm{ppm}$ and acquired into 2048 data points (acquisition time $=0.17 \mathrm{~s}$ ) with a relaxation delay of 1.5 seconds for a total accumulation time of 117 minutes. The $\omega_{1}$ frequency was centred at $-40 \mathrm{ppm}$ over a frequency width of $100.0163 \mathrm{ppm}$.

Additional data including $1 \mathrm{D}{ }^{31} \mathrm{P}-\left\{{ }^{1} \mathrm{H}\right\}$ and $2 \mathrm{D}\left[{ }^{1} \mathrm{H}\right.$, $\left.{ }^{1} \mathrm{H}\right]$ TOCSY, COSY, and NOESY NMR data were acquired in order to verify the nature of certain products. Variable temperature measurements for $\mathrm{d}(\mathrm{GCGsAGC})_{2}$ were carried out on a $2 \mathrm{mM}$ solution of the sample in $\mathrm{D}_{2} \mathrm{O}$ between 278 and $353 \mathrm{~K}$ in temperature intervals of $5 \mathrm{~K}$. Duplex formation was verified by $2 \mathrm{D}\left[{ }^{1} \mathrm{H},{ }^{1} \mathrm{H}\right]$ NOESY NMR spectroscopy and compared with previously acquired data for $\mathrm{d}(\mathrm{GCGAGC})_{2}$.

2.5. Molecular Modelling. Molecular models were built and energy minimized using the Biopolymer module of Sybyl (Version 6.3, Tripos Inc.) running on a Silicon Graphics $\mathrm{O}_{2}$ workstation (R12000 processor) under IRIX version 6.5.

\section{Results}

3.1. Reaction with Model Dimer Nucleotides. Model reactions were initially carried out with molecules possessing the structural features associated with specific target sites in the ODN reactions with $\mathrm{I}$. The outcome of monitoring the reaction of each isolated dimer subunit by $2 \mathrm{D}\left[{ }^{1} \mathrm{H},{ }^{15} \mathrm{~N}\right]$ HSQC NMR spectroscopy is shown summarized as a single reaction snapshot in each case (Figure 1).

3.1.1. Reactions with $d(G p G)$ and $R, S-d(G s G)$. Reaction of I with the control dimer $\mathrm{d}(\mathrm{GpG})$, II, followed the classical route observed when monitoring the reaction of the chloro form of $\mathbf{I}$, cisplatin, with $\mathrm{d}(\mathrm{GpG})$ containing ODNs [19-24]. Initial formation of the monoaqua adduct, cis$\left[\mathrm{Pt}\left({ }^{15} \mathrm{NH}_{3}\right)_{2} \mathrm{I}\left(\mathrm{H}_{2} \mathrm{O}\right)\right]^{+}$occurred by aquation for which the 2D $\left[{ }^{1} \mathrm{H},{ }^{15} \mathrm{~N}\right]$ HSQC NMR data displayed cross-peaks associated with ${ }^{15} \mathrm{~N}$ trans to $\mathrm{I}, \delta\left({ }^{15} \mathrm{~N} /{ }^{1} \mathrm{H}\right)=-47.51 / 4.08 \mathrm{ppm}$ (1 in Figure $1(\mathrm{a}))$ and ${ }^{15} \mathrm{~N}$ trans to $\mathrm{O}, \delta\left({ }^{15} \mathrm{~N} /{ }^{1} \mathrm{H}\right)=$ $-90.09 / 3.70$ ppm (2 in Figure 1(a)). Displacement of $\mathrm{H}_{2} \mathrm{O}$ from the monoaqua species by $N 7$ of a guanine residue resulted in the formation of a molecule in which ${ }^{15} \mathrm{~N}$ was trans to $N 7$ and to I, which, following intermediate formation of a further monoaqua species, formed the final classical ring closed 1,2-d(GpG) intrastrand cross-link via both guanine $N 7$ centres. This final product is typified by ${ }^{15} \mathrm{~N}$ trans to two $N 7$ centres with characteristic $2 \mathrm{D}\left[{ }^{1} \mathrm{H},{ }^{15} \mathrm{~N}\right]$ HSQC NMR correlations at $\delta\left({ }^{15} \mathrm{~N} /{ }^{1} \mathrm{H}\right)=-68.13 / 4.43$ and $-68.51 / 4.35$ ppm (cross-peaks 3 and 4 in Figure 1(a)).

Comparison of this reaction profile with the outcome from that of the reaction between I and the phosphorothioate substituted dimer $R, S-\mathrm{d}(\mathrm{GsG})$ (IIs) indicated close similarity to the previous report [14] in which the main product was an
$N, S$-macrochelate formed through linkage of the platinum centre to both the phosphorothioate sulphur $\left({ }^{15} \mathrm{~N}\right.$ trans to $S, \delta\left({ }^{15} \mathrm{~N} /{ }^{1} \mathrm{H}\right)=-50.10 / 4.35 \mathrm{ppm}, 5$ in Figure $\left.1(\mathrm{~b})\right)$ and to $N 7$ of one guanine residue $\left({ }^{15} \mathrm{~N}\right.$ trans to $N 7, \delta\left({ }^{15} \mathrm{~N} /{ }^{1} \mathrm{H}\right)=$ $-69.33 / 4.15 \mathrm{ppm}, 6$ in Figure 1(b)). Although forming the main product, as indicated by the intensity of the cross-peaks in the $2 \mathrm{D}\left[{ }^{1} \mathrm{H},{ }^{15} \mathrm{~N}\right]$ HSQC NMR data, some formation of an N7, N7 cross-link also occurred, although to a much lesser extent, as indicated by the presence of cross-peaks at the same chemical shifts as those for $\mathbf{3}$ and $\mathbf{4}$ in Figure 1(a) for the reaction with $\mathrm{d}(\mathrm{GpG})$. Thus, whilst the reaction with dimer $\mathrm{d}(\mathrm{GpG})$, II, followed the classical route in only forming cis- $\left[\mathrm{Pt}\left({ }^{15} \mathrm{NH}_{3}\right)_{2}\{\mathrm{~d}(\mathrm{GpG})\}-N 7, N 7\right]^{2+}$, reaction with dimer $\mathrm{d}(\mathrm{GsG})$, IIs, was dominated by the presence of the cis- $\left[\mathrm{Pt}\left({ }^{15} \mathrm{NH}_{3}\right)_{2}\{\mathrm{~d}(\mathrm{GsG})\}-S, N 7\right]^{2+}$ macrochelate, indicating preference by platinum for reaction at sulphur according to the principles of HSAB chemistry [25] and in line with previous findings [14]. Thus, as an isolated structural element, it is clear that sufficient reactivity and structural flexibility exists in the dimer $\mathrm{d}(\mathrm{Gs} G)$, IIs, to form the $\mathrm{S}, N$ macrochelate in the same manner as that reported previously for the self-complementary duplex ODN $R, S-5^{\prime}$ d(TATGsGCCATA $)_{2}-3^{\prime}$.

3.1.2. Reactions with $d(G p A)$ and $R, S-d(G s A)$. Reaction profiles of I with dimers $\mathrm{d}(\mathrm{GpA})$, III, and $\mathrm{d}(\mathrm{GsA})$, IIIs, form valuable corollaries with these guanine-only dimer analogues. As shown for III (Figure 1(c)), initial aquation occurred to form the monoaqua, monoiodo species giving rise to cross-peaks in the $2 \mathrm{D}\left[{ }^{1} \mathrm{H},{ }^{15} \mathrm{~N}\right]$ HSQC NMR data at the same chemical shift positions labelled $\mathbf{1}$ and $\mathbf{2}$ in Figure 1(a). Low intensity cross-peaks were also present (not visible in Figure $1(\mathrm{c})$ ) at $\delta\left({ }^{15} \mathrm{~N} /{ }^{1} \mathrm{H}\right)=-47.85 / 4.27 \mathrm{ppm}$ $\left({ }^{15} \mathrm{~N}\right.$ trans to $\left.\mathrm{I}\right)$ and at $\delta\left({ }^{15} \mathrm{~N} /{ }^{1} \mathrm{H}\right)=-76.02 / 4.07 \mathrm{ppm}$ $\left({ }^{15} \mathrm{~N}\right.$ trans to $\left.\mathrm{N}\right)$ indicative of some reaction to form cis$\left[\mathrm{Pt}\left({ }^{15} \mathrm{NH}_{3}\right)_{2} \mathrm{I}\{\mathrm{d}(\mathrm{GpA})\}-\mathrm{G}-\mathrm{N} 7\right]^{+}$. Two low intensity crosspeaks also appeared at $\delta\left({ }^{15} \mathrm{~N} /{ }^{1} \mathrm{H}\right)=-65.88 / 4.48$ and $-66.55 / 4.43$ ppm (7 and 8, resp., in Figure 1(c)) indicative of a 1,2-d(G-N7,A-N7) macrochelate in which the platinum centre is bound to $N 7$ of both the $5^{\prime}-\mathrm{G}$ and $3^{\prime}-\mathrm{A}$. The reaction of III with I was slow by comparison with the same reaction for II, a feature expected for the less electron-rich adenine $N 7$ centre with adenine also located in the $3^{\prime}$-position that is more normally favoured for initial platinum substitution in duplex $\mathrm{d}(\mathrm{GpG})$ environments [26, 27].

The contrast to this result lies in examining the consequences of the reaction between I and IIIs, namely, with the phosphorothioate dimer $R, S-\mathrm{d}(\mathrm{GsA})$. As shown for this reaction (Figure $1(\mathrm{~d})$ ), a collection of closely grouped cross-peaks appeared in the 2D $\left[{ }^{1} \mathrm{H},{ }^{15} \mathrm{~N}\right]$ HSQC NMR data. During the initial phase of this reaction, cross-peaks appeared, which were consistent with formation of cis$\left[\mathrm{Pt}\left({ }^{15} \mathrm{NH}_{3}\right)_{2} \mathrm{I}\left(\mathrm{H}_{2} \mathrm{O}\right)\right]^{+}$along with simultaneous appearance of cross-peaks at $\delta\left({ }^{15} \mathrm{~N} /{ }^{1} \mathrm{H}\right)=-46.56 / 4.14,-45.64 / 4.11$ $\left({ }^{15} \mathrm{~N}\right.$ trans to $\left.\mathrm{S}\right)$ and $-54.46 / 3.95 \mathrm{ppm}\left({ }^{15} \mathrm{~N}\right.$ trans to I) indicating rapid formation of the $R$ and $S$ cis$\left[\mathrm{Pt}\left({ }^{15} \mathrm{NH}_{3}\right)_{2} \mathrm{I}\{\mathrm{d}(\mathrm{GsA})\}-\mathrm{S}\right]^{+}$adduct of $\mathrm{d}(\mathrm{GsA})$. The reaction evolved producing only cross-peaks within the region indicated (Figure $1(\mathrm{~d})$ ) suggesting that only products that are 


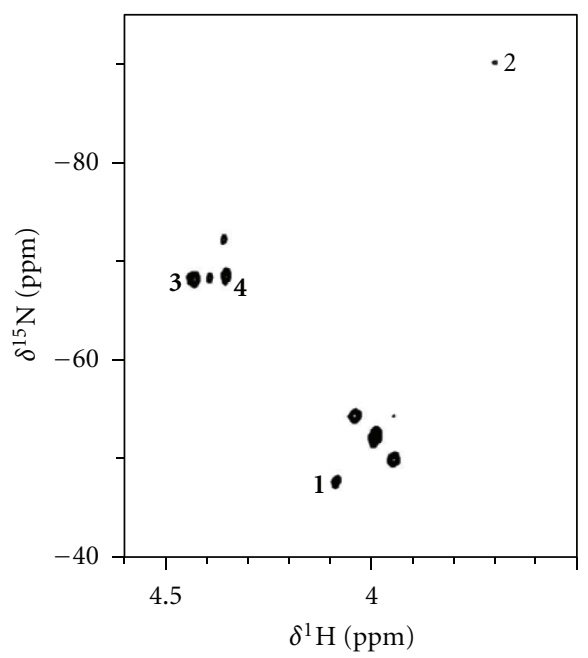

(a)

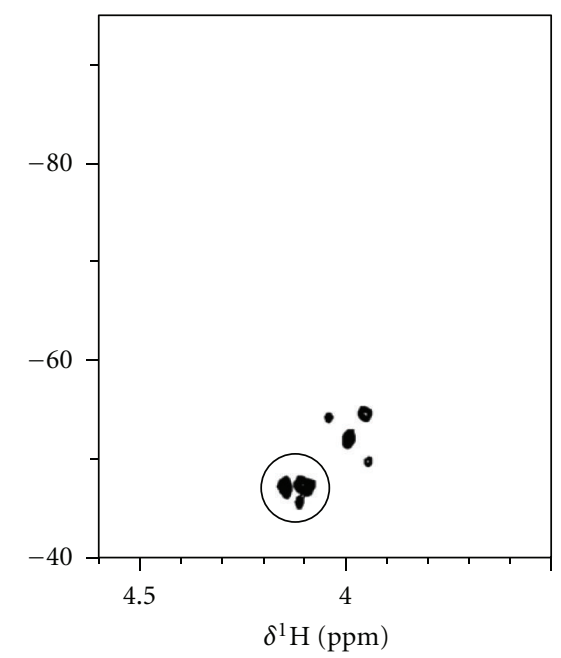

(d)

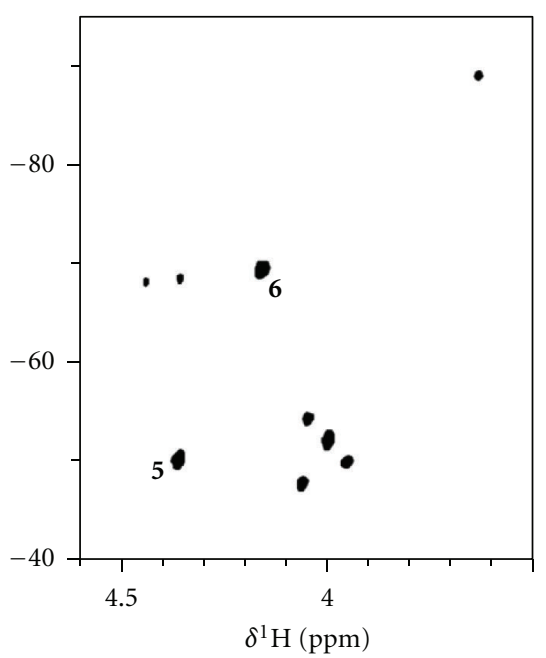

(b)

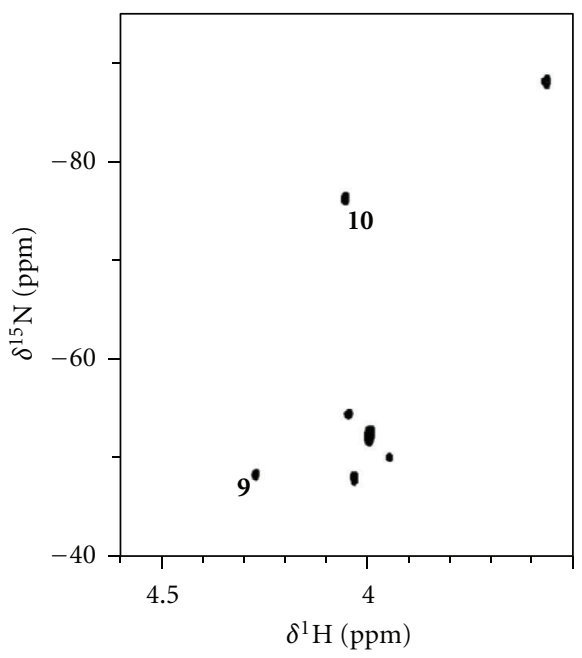

(e)

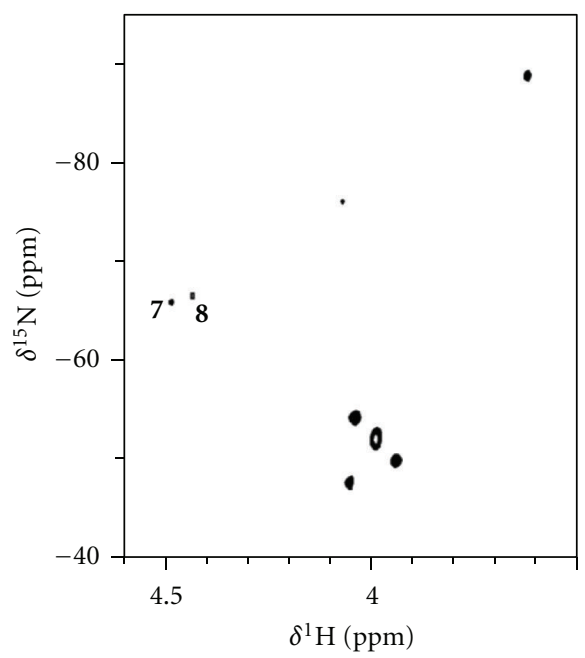

(c)

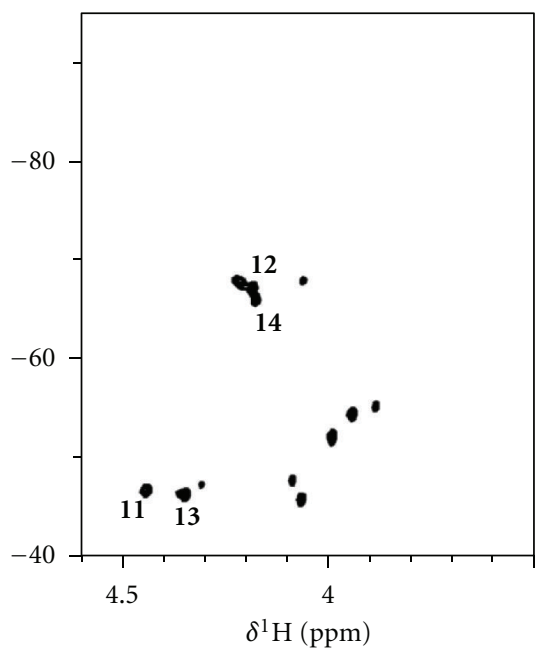

(f)

Figure 1: Snapshots from 2D $\left[{ }^{1} \mathrm{H},{ }^{15} \mathrm{~N}\right]$ HSQC NMR data for reactions between $\left[\mathrm{Pt}\left({ }^{15} \mathrm{NH}_{3}\right)_{2} \mathrm{I}_{2}\right], \mathbf{I}$, and dimer ODNs. (a) d(GpG), II; (b) $R, S-\mathrm{d}(\mathrm{GsG})$, IIs; (c) d(GpA), III; (d) R,S-d(GsA), IIIs; (e) d(GpT), IV; (f) $R, S-\mathrm{d}(\mathrm{GsT})$, IVs. See text for details of numbered items.

substituted with either S or I form. The most intense crosspeaks appeared at $\delta\left({ }^{15} \mathrm{~N} /{ }^{1} \mathrm{H}\right)=-47.37 / 4.14,-47.44 / 4.10$, and $-47.08 / 4.09 \mathrm{ppm}\left({ }^{15} \mathrm{~N}\right.$ trans to $\left.\mathrm{S}\right)$ along with the crosspeak at $\delta\left({ }^{15} \mathrm{~N} /{ }^{1} \mathrm{H}\right)=-54.46 / 3.95 \mathrm{ppm}\left({ }^{15} \mathrm{~N}\right.$ trans to I). It was not clear from these data what the structural source of the differences in the chemical shift positions of these cross-peaks was. However, the key point regarding this was that there was no evidence for substitution at Pt by $N 7$ since cross-peaks at chemical shifts typical of ${ }^{15} \mathrm{~N}$ trans to nitrogen did not appear in the data. This is of immediate interest in comparing the data with the reaction of the dimer $R, S-\mathrm{d}(\mathrm{Gs} G)$, IIs, with $\mathbf{I}$ in which formation of the $N, S$ macrochelate was favoured. The suggestion indicated by these comparisons is that macrochelate formation to form an $S, N$ macrochelate occurs with bond formation between the platinum centre and the N7 associated with the base, which is $3^{\prime}$ to the phosphorothioate substitution position. This had been proposed previously [14], but for the duplex
$R, S$-d(TATGsGCCATA) $)_{2}$ it was not possible to categorically establish this fact. Hence it is clear for the first time from this work that macrochelate formation to $N 7$ for a platinum centre attached to a phosphorothioate sulphur in a DNA phosphodiester backbone occurs only to an electron-rich nitrogen (in this case G-N7) which is associated with a base $3^{\prime}$ to the phosphorothioate substitution position. The lower reactivity of adenine at the $3^{\prime}$ position towards platinum and the presence of $\mathrm{G}$ in a position $5^{\prime}$ to the phosphorothioate both mitigate against formation of an $S, N$ macrochelate, suggesting that the reaction between I and d(GsA), IIIs, stops at formation of products in which ammine on platinum is trans to either S or I.

3.1.3. Reaction with $d(G p T)$ and $R, S-d(G s T)$. In order to explore the reactivity associated with different phosphodiester and phosphorothioate containing DNA backbone geometries, it was also helpful to explore the reactivity of 
TABLe $1:{ }^{15} \mathrm{~N} /{ }^{1} \mathrm{H}$ chemical shifts of $2 \mathrm{D}\left[{ }^{1} \mathrm{H},{ }^{15} \mathrm{~N}\right]$ HSQC NMR cross-peaks for the reactions of dimer nucleic acids with $\left[\mathrm{Pt}\left({ }^{15} \mathrm{NH}\right)_{3} \mathrm{I}_{2}\right]$.

\begin{tabular}{|c|c|c|c|c|c|}
\hline Sample & Code & Complex & Peak & $\delta\left({ }^{15} \mathrm{~N} /{ }^{1} \mathrm{H}\right)$ & ${ }^{15} \mathrm{~N}$ trans to \\
\hline & I & cis- $\left[\mathrm{Pt}\left({ }^{15} \mathrm{NH}_{3}\right)_{2} \mathrm{I}_{2}\right]$ & & $-52.12 / 3.99$ & I \\
\hline & & $c i s-\left[\mathrm{Pt}\left({ }^{15} \mathrm{NH}_{3}\right)_{2} \mathrm{I}\left(\mathrm{H}_{2} \mathrm{O}\right)\right]^{+}$ & 1 & $-47.51 / 4.08$ & I \\
\hline & & & 2 & $-90.09 / 3.70$ & $\mathrm{O}$ \\
\hline \multirow[t]{2}{*}{$\mathrm{d}(\mathrm{GpG})$} & II & $c i s-\left[\mathrm{Pt}\left({ }^{15} \mathrm{NH}_{3}\right)_{2}\{\mathrm{~d}(\mathrm{GpG})\}-N 7, N 7\right]^{2+}$ & 3 & $-68.13 / 4.43$ & $\mathrm{~N}$ \\
\hline & & & 4 & $-68.51 / 4.35$ & $\mathrm{~N}$ \\
\hline \multirow[t]{2}{*}{$R, S-\mathrm{d}(\mathrm{GsG})$} & IIs & cis- $\left[\mathrm{Pt}\left({ }^{15} \mathrm{NH}_{3}\right)_{2} \mathrm{~d}(\mathrm{GsG})-\mathrm{S}, \mathrm{N} 7\right]^{2+}$ & 5 & $-50.10 / 4.35$ & S \\
\hline & & & 6 & $-69.33 / 4.15$ & $\mathrm{~N}$ \\
\hline \multirow[t]{2}{*}{$\mathrm{d}(\mathrm{GpA})$} & III & cis- $\left[\mathrm{Pt}\left({ }^{15} \mathrm{NH}_{3}\right)_{2}\{\mathrm{~d}(\mathrm{GpA})\}-\mathrm{G}-\mathrm{N} 7, \mathrm{~A}-\mathrm{N} 7\right]^{2+}$ & 7 & $-65.88 / 4.48$ & $\mathrm{~N}$ \\
\hline & & & 8 & $-66.55 / 4.43$ & $\mathrm{~N}$ \\
\hline \multirow[t]{2}{*}{$R, S-\mathrm{d}(\mathrm{GsA})$} & IIIs & $c i s-\left[\mathrm{Pt}\left({ }^{15} \mathrm{NH}_{3}\right)_{2}\{\mathrm{~d}(\mathrm{GsA})\}-I, S\right]^{+}$ & - & $-47.44 / 4.10^{*}$ & S \\
\hline & & & & $-54.46 / 3.95$ & I \\
\hline \multirow[t]{2}{*}{$\mathrm{d}(\mathrm{GpT})$} & IV & cis- $\left[\mathrm{Pt}\left({ }^{15} \mathrm{NH}_{3}\right)_{2} \mathrm{Id}(\mathrm{GpT})-\mathrm{T}-\mathrm{N} 3\right]^{+}$ & 9 & $-48.22 / 4.26$ & I \\
\hline & & & 10 & $-76.13 / 4.05$ & $\mathrm{~N}$ \\
\hline \multirow[t]{4}{*}{$R, S-\mathrm{d}(\mathrm{GsT})$} & IVs & R or $\mathrm{S}$ cis- $\left[\mathrm{Pt}\left({ }^{15} \mathrm{NH}_{3}\right)_{2}\{\mathrm{~d}(\mathrm{GsT})\}-\mathrm{T}-\mathrm{N} 3, \mathrm{~S}\right]^{2+}$ & 11 & $-46.55 / 4.34$ & $\mathrm{~S}$ \\
\hline & & & 12 & $-67.05 / 4.18$ & $\mathrm{~N}$ \\
\hline & & S or $R$ cis- $\left[\mathrm{Pt}\left({ }^{15} \mathrm{NH}_{3}\right)_{2}\{\mathrm{~d}(\mathrm{GsT})\}-\mathrm{T}-\mathrm{N} 3, S\right]^{2+}$ & 13 & $-46.25 / 4.35$ & S \\
\hline & & & 14 & $-65.97 / 4.17$ & $\mathrm{~N}$ \\
\hline
\end{tabular}

${ }^{*}$ Representative value.

"GT", being present in hairpin loop arrangements [28, 29]. Reactions with both $\mathrm{d}(\mathrm{GpT})$ (IV) and $\mathrm{d}(\mathrm{GsT})$ (IVs) were, therefore, monitored in order to make comparisons with the reactions between these with $\mathbf{I}$ and those of the dimer sequences already considered here. The reaction of I with IV, $\mathrm{d}(\mathrm{GpT})$, is represented by the $2 \mathrm{D}\left[{ }^{1} \mathrm{H},{ }^{15} \mathrm{~N}\right]$ HSQC NMR data shown in Figure 1(e). Two cross-peaks 1 and $\mathbf{2}$ indicated the presence of the monoaqua species cis- $\left[\mathrm{Pt}\left({ }^{15} \mathrm{NH}_{3}\right)_{2} \mathrm{I}\left(\mathrm{H}_{2} \mathrm{O}\right)\right]^{+}$ as shown for similar instances (Figures $1(\mathrm{a})-1(\mathrm{c})$ ). Two additional cross-peaks, $9\left(\delta\left({ }^{15} \mathrm{~N} /{ }^{1} \mathrm{H}\right)=-48.22 / 4.26 \mathrm{ppm},{ }^{15} \mathrm{~N}\right.$ trans to $\mathrm{I})$ and $10\left(\delta\left({ }^{15} \mathrm{~N} /{ }^{1} \mathrm{H}\right)=-76.13 / 4.05 \mathrm{ppm},{ }^{15} \mathrm{~N}\right.$ trans to $\mathrm{N}$ ) indicated formation of a bond between platinum and nitrogen on one of the two bases. Since it is clear from data presented for II and III, supported by data for IIs and IIIs, and in line with previous precedent [14] that reaction of cis- $\left[\mathrm{Pt}\left({ }^{15} \mathrm{NH}_{3}\right)_{2} \mathrm{I}\left(\mathrm{OH}_{2}\right)\right]^{+}$occurs very slowly with $5^{\prime}-\mathrm{G}$ N7 compared with reacting centres associated with bases in the $3^{\prime}$ position, it was clear that cross-peak 10 (trans to $\mathrm{N})$ arose from attachment of platinum at the thymidine $\mathrm{N3}$ atom to form cis- $\left[\mathrm{Pt}\left({ }^{15} \mathrm{NH}_{3}\right)_{2} \mathrm{I}\{\mathrm{d}(\mathrm{GpT})\}-\mathrm{T}-\mathrm{N} 3\right]^{+}$. Evidence for additional formation of a macrochelate was based on low intensity 2D $\left[{ }^{1} \mathrm{H},{ }^{15} \mathrm{~N}\right]$ HSQC NMR cross-peaks at $\delta\left({ }^{15} \mathrm{~N} /{ }^{1} \mathrm{H}\right)=-66.5 / 4.33$ and $-67.97 / 4.31 \mathrm{ppm}$, which fitted with substitution at both G-N7 and T-N3 thereby creating cis- $\left[\mathrm{Pt}\left({ }^{15} \mathrm{NH}_{3}\right)_{2}\{\mathrm{~d}(\mathrm{GpT})\}-\mathrm{G}-\mathrm{N} 7, \mathrm{~T}-\mathrm{N} 3\right]^{2+}$. Modelling studies supported the assertion that sufficient flexibility and number of degrees of freedom allow this adduct to form and for which precedence exists in relation to platinum binding at T-N3. Given this, it is clear from the data associated with $R, S-\mathrm{d}$ (GsT) (IVs) that substitution at sulphur is most likely combined with substitution at T-N3. Cross-peaks in the $2 \mathrm{D}$ $\left[{ }^{1} \mathrm{H},{ }^{15} \mathrm{~N}\right] \mathrm{HSQC}$ NMR data at $\delta\left({ }^{15} \mathrm{~N} /{ }^{1} \mathrm{H}\right)=-46.55 / 4.34\left({ }^{15} \mathrm{~N}\right.$ trans to $\mathrm{S}, 11$ in Figure $1(\mathrm{f}))$ and $-67.05 / 4.18 \mathrm{ppm}\left({ }^{15} \mathrm{~N}\right.$ trans to $\mathrm{N}, 12$ in Figure $1(\mathrm{f}))$ and at $\delta\left({ }^{15} \mathrm{~N} /{ }^{1} \mathrm{H}\right)=-46.25 / 4.35\left({ }^{15} \mathrm{~N}\right.$ trans to S, 13 in Figure $1(\mathrm{f}))$ and $-65.97 / 4.17 \mathrm{ppm}\left({ }^{15} \mathrm{~N}\right.$ trans to N, 14 in Figure 1(f)) were consistent with two different cis$\left\{\mathrm{Pt}\left({ }^{15} \mathrm{NH}_{3}\right)_{2}-\mathrm{N}, \mathrm{S}\right\}^{2+}$ macrochelates in which $\mathrm{Pt}$ was bound to both phosphorothioate $\mathrm{S}$ and simultaneously to T-N3. These data are summarized in Table 1.

\subsection{Reactions with Oligonucleotide Constructs}

3.2.1. Reactions with ODNs Containing Central GpG and $R, S-G s G$ Sequences. NMR studies of the dimer nucleic acids reacting with I served as a prelude to investigating the same reaction schemes but in the context of more structured nucleic acid domains. Previous studies had concluded that reaction by I at "GpG" and "GsG" within the framework of longer ODNs progressed according to different routes, reaction with "GpG" resulting in formation of cis- $\left[\mathrm{Pt}\left({ }^{15} \mathrm{NH}_{3}\right)_{2}\{\mathrm{~d}(\mathrm{GpG})\}-N 7, N 7\right]^{2+}$ in contrast to cis- $\left[\mathrm{Pt}\left({ }^{15} \mathrm{NH}_{3}\right)_{2}\{\mathrm{~d}(\mathrm{GsG})\}-S, \mathrm{G}-N 7\right]^{2+}$ in the case of the "d(GsG)" phosphorothioate containing self-complementary ODN duplex d(TATGsGCCATA) $)_{2}$. Studies with the latter were complicated by the fact that two "GsG" sites existed per duplex, further confounded by the presence of two possible diastereoisomers for each strand at the "GsG" site. In order to reduce the complexity of the resulting data in this work, a single instance of "GsG" was incorporated into a DNA duplex context, namely, $5^{\prime}$-d(ATATGsGTATA) $-3^{\prime} \cdot 5^{\prime}$ d(TATACCATAT) $-3^{\prime}$, Vs, and its reaction with I was compared with that of the single strand $5^{\prime}-\mathrm{d}$ (ATATGpG ${ }^{6}$ TATA)$3^{\prime}(\mathbf{V})$. Results from monitoring these reactions by $2 \mathrm{D}\left[{ }^{1} \mathrm{H}\right.$, ${ }^{15} \mathrm{~N}$ ] HSQC NMR spectroscopy are shown in Figures 2(a) and $2(\mathrm{~b})$.

For $\mathbf{V}$, aquation is keenly followed by formation of the monoiodo, mono-guanine- $N 7$ adduct cis- $\left[\mathrm{Pt}\left({ }^{15} \mathrm{NH}_{3}\right)_{2} \mathrm{I}\right.$ $\left.\left\{\mathrm{d}\left(\mathrm{V}-\mathrm{G}^{6}-\mathrm{N} 7\right)\right\}\right]^{+}$for which $\delta\left({ }^{15} \mathrm{~N} /{ }^{1} \mathrm{H}\right)=-47.43 / 4.39(\mathbf{1 5}$, 


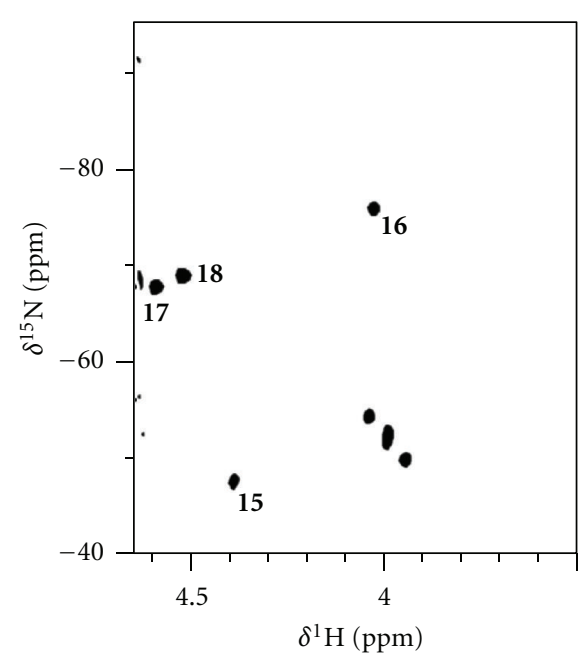

(a)

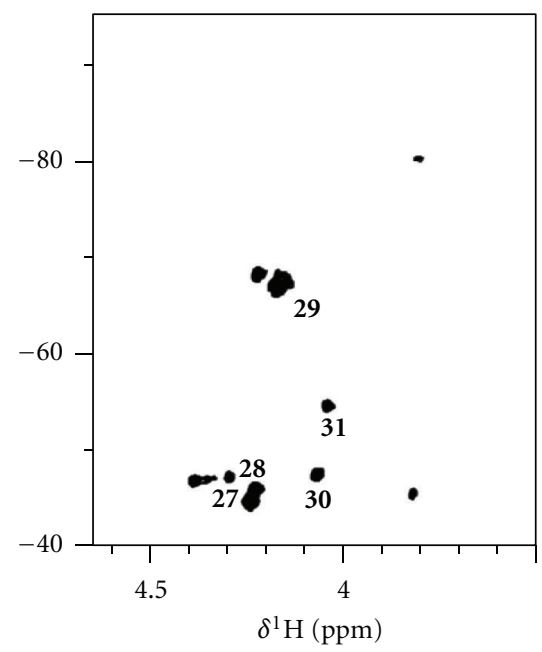

(d)

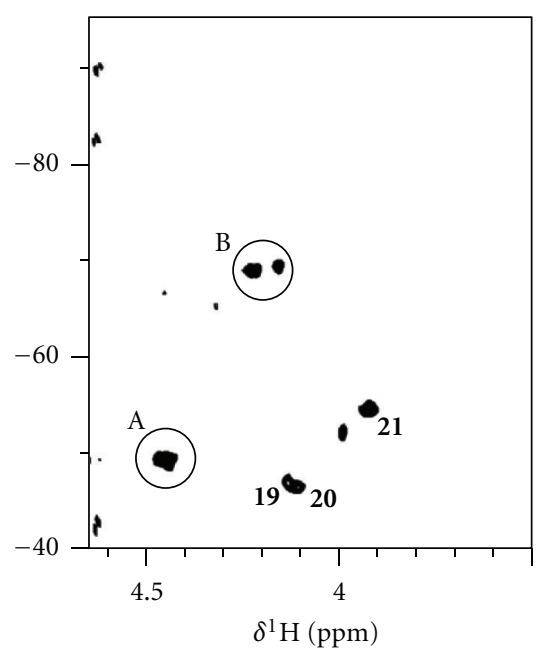

(b)

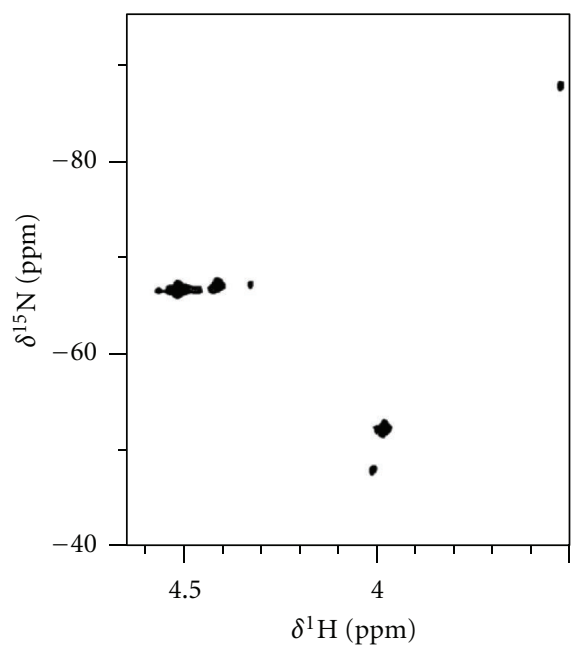

(e)

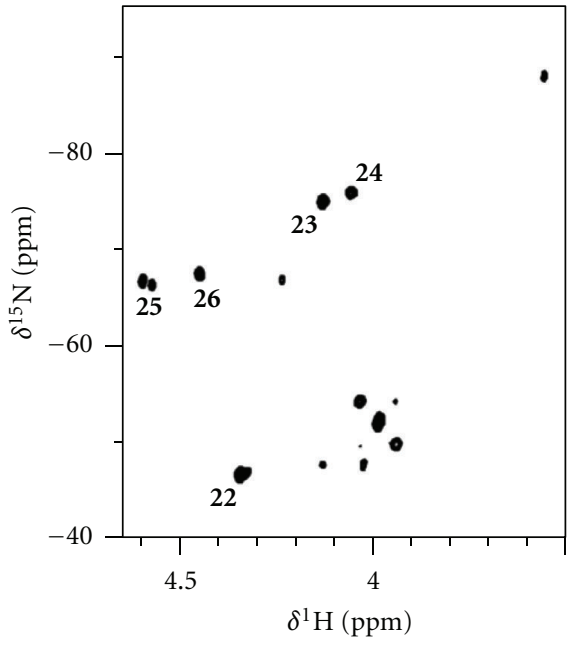

(c)

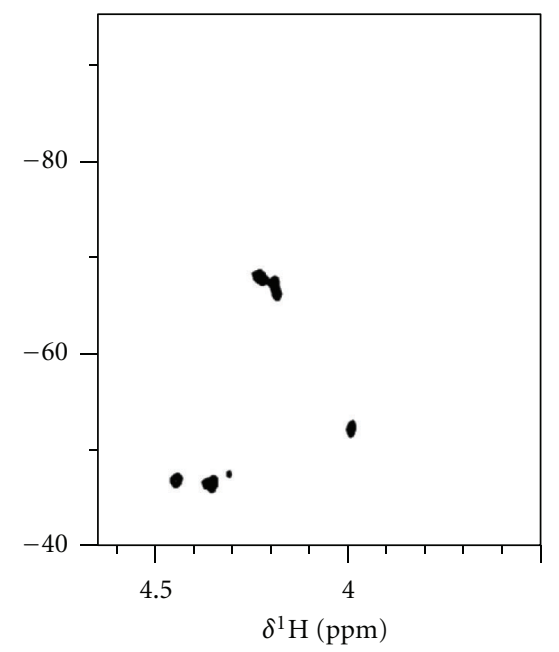

(f)

FIGURE 2: Snapshots from 2D $\left[{ }^{1} \mathrm{H},{ }^{15} \mathrm{~N}\right]$ HSQC NMR data for reactions between $\left[\mathrm{Pt}\left({ }^{15} \mathrm{NH}_{3}\right)_{2} \mathrm{I}_{2}\right]$, I, and longer ODNs. (a) d(ATATGpGTATA) single strand; (b) R,S-d(ATATGsGTATA) - d(TATACCATAT) duplex, Vs; (c) d(GCGpAGC) ${ }_{2}$ duplex, VI; (d) R,S-d(GCGsAGC) ${ }_{2}$ duplex, VIs; (e) d(CGCGpTGCG), VII; (f) $R, S$-d(CGCGsTGCG), VIIs. See text for details of numbered items.

${ }^{15} \mathrm{~N}$ trans to I) and $-75.56 / 4.02 \mathrm{ppm}\left(16,{ }^{15} \mathrm{~N}\right.$ trans to $\left.\mathrm{G}^{6}-\mathrm{N7}\right)$. The reaction ran to completion by formation of the cross-linked species cis- $\left[\mathrm{Pt}\left({ }^{15} \mathrm{NH}_{3}\right)_{2}\left\{\mathrm{~d}\left(\mathbf{V}-\mathrm{G}^{5}-\mathrm{N} 7, \mathrm{G}^{6}-\right.\right.\right.$ N7) $\}]^{2+}$ for which $\delta\left({ }^{15} \mathrm{~N} /{ }^{1} \mathrm{H}\right)=-67.49 / 4.59$ and $-68.68 /$ $4.52 \mathrm{ppm}\left({ }^{15} \mathrm{~N}\right.$ trans to $\mathrm{G}^{5 / 6}-\mathrm{N} 7$, peaks 17 and $\mathbf{1 8}$ in Figure 2(a)).

In contrast, the reaction of duplex Vs with I (Figure 2(b)) followed a similar route to that observed for $R, S$-d (GsG) (IIs, Figure 1(b)). No direct evidence existed for the monoaquation step in this case but instead the reaction appeared to proceed directly via substitution at platinum, with sulphur replacing iodide to form the monoiodo, monosulphur species $R, S$-cis- $\left[\mathrm{Pt}\left({ }^{15} \mathrm{NH}_{3}\right)_{2} \mathrm{I}\{\mathrm{d}(\mathbf{V s}-\mathrm{S})\}\right]^{+}$arising from reaction at the phosphorothioate sulphur atom $\left(\delta\left({ }^{15} \mathrm{~N} /{ }^{1} \mathrm{H}\right)=\right.$ $-46.76 / 4.13$ and $-46.30 / 4.10 \mathrm{ppm}$ for ${ }^{15} \mathrm{~N}$ trans to $\mathrm{S}$, two diastereoisomers being distinguished, peaks 19 and 20 of Figure 2(b), and $\delta\left({ }^{15} \mathrm{~N} /{ }^{1} \mathrm{H}\right)=-54.35 / 3.92$ for ${ }^{15} \mathrm{~N}$ trans to
I, peak 21 of double intensity compared with 19 and 20). Substitution of the remaining iodide ligand then occurred by reaction at $\mathrm{G}^{6}-N 7$ to form the $S, N$ macrochelate. Two clusters of cross-peaks arose from different forms of this product: those due to ${ }^{15} \mathrm{~N}$ trans to $\mathrm{S}$ occurring at $\delta\left({ }^{15} \mathrm{~N} /{ }^{1} \mathrm{H}\right)$ $=-49.04 / 4.44$ (lower intensity peak) and $-49.23 / 4.46 \mathrm{ppm}$ (higher intensity peak) (cluster A, Figure 2(b)); those due to ${ }^{15} \mathrm{~N}$ trans to $\mathrm{G}^{6}-\mathrm{N} 7$ occurring at $\delta\left({ }^{15} \mathrm{~N} /{ }^{1} \mathrm{H}\right)=-68.77 / 4.22$, $-68.77 / 4.21$, and $-69.12 / 4.15 \mathrm{ppm}$ (equal intensity of peaks, cluster B, Figure 2(b)). Qualitatively, the ease by which this process occurred appeared to be more direct compared with the reaction for the dimer $R, S-\mathrm{d}(\mathrm{GsG})$, IIs. It is probable that the context of a more restricted conformational environment (i.e., fewer degrees of rotational freedom) formed by the DNA duplex structure allows the $S, \mathrm{G}^{6}-N 7$ macrochelate to form more readily compared with the less formally structured $d(G s G)$ dimer, II. For additional comparison, 


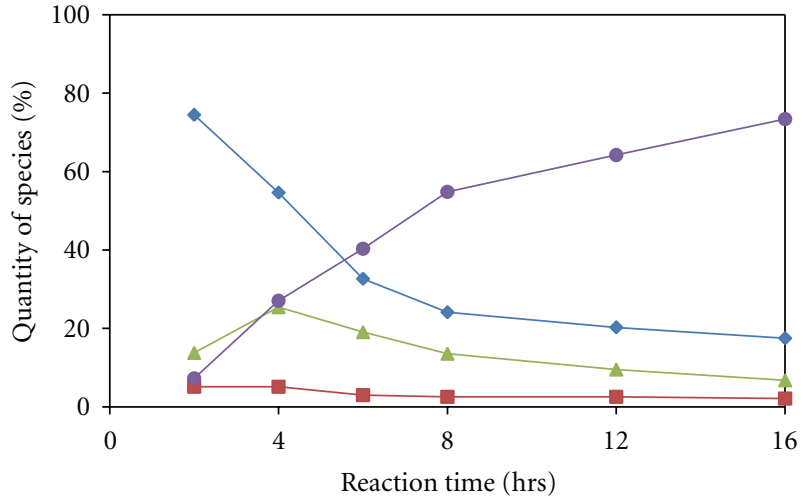

FIGURE 3: Evolution of the reaction profile for I, cis- $\left[\mathrm{Pt}\left({ }_{15} \mathrm{NH}_{3}\right)_{2} \mathrm{I}_{2}\right]$ with the DNA single-strand $R, S$-d(ATATGsGTATA) containing a single phosphorothioate substitution, recorded as a function of time based on integration of $2 \mathrm{D}\left[{ }^{1} \mathrm{H},{ }^{15} \mathrm{~N}\right]$ HSQC NMR data acquired at a magnetic field strength of $14.1 \mathrm{~T}\left({ }^{1} \mathrm{H}=600 \mathrm{MHz}\right)$. Key: blue diamond: cis- $\left[\mathrm{Pt}\left({ }^{15} \mathrm{NH}_{3}\right)_{2} \mathrm{I}_{2}\right]$ starting material; red square: cis- $\left[\mathrm{Pt}\left({ }^{15} \mathrm{NH}_{3}\right)_{2} \mathrm{I}\left(\mathrm{OH}_{2}\right)\right]^{+}$monoaqua, monoiodo adduct; green triangle: cis- $\left[\mathrm{Pt}\left({ }^{15} \mathrm{NH}_{3}\right)_{2} \mathrm{I}, S\right]^{+}$monoiodo, mono-phosphorothioate adduct; violet circle: cis- $\left[\mathrm{Pt}\left({ }^{15} \mathrm{NH}_{3}\right)_{2} S, \mathrm{G}_{6}-\mathrm{N} 7\right]^{2+}$ reaction end product.

the same reaction was monitored for the single-strand decamer ODN $R, S-5^{\prime}$-d(ATATGsGTATA)-3'. This showed more evidence of the buildup of the monoaqua, monoiodo intermediate (Figure 3), indicating that for the less structured instances of $\mathrm{d}(\mathrm{GsG})$ dimer and "GsG" incorporated into a longer single strand, the ring closing event to form the $S, N$ macrochelate is much less favoured, and this is ascribed to greater conformational freedom when compared with a DNA duplex environment. The reaction profile associated with duplex Vs (Figure 4) clearly indicated rapid initial conversion of the starting material to the monoiodo, monosulphur adduct, which further converted to the end product in a time frame that was shorter than for the singlestrand ODN d(ATATGsGTATA). Thus after 6 hours, $40 \%$ of the end product had formed in this case compared with $63 \%$ in the same period for Vs. At the same time, a considerable quantity of the starting material remained in the reaction medium associated with the single strand, whereas for Vs the starting material had been almost completely consumed and converted into the monoiodo, monosulphur adduct.

\subsubsection{ODNs Containing Central GpA and R,S-GsA Sequences.}

To explore the effects of different nucleic acid topologies on the course of the reaction with I, two further DNA sequences were selected for reaction monitoring using the same approach as that described in the preceding section. The first of these sequences, $5^{\prime}-\mathrm{d}(\mathrm{GCG} * \mathrm{AGC})-3^{\prime}$, where $*$ represents either phosphodiester or phosphorothioate linkages (VI and VIs resp.), is unusual as a mismatch sequence since it forms an extremely temperature stable duplex structure for such a short hexameric nucleic acid of approximately half a turn of helix and possessing tandem sheared zipper-like GA mismatches at the centre $[30,31]$. Such sheared base pairing occurs often in biological systems especially in the context

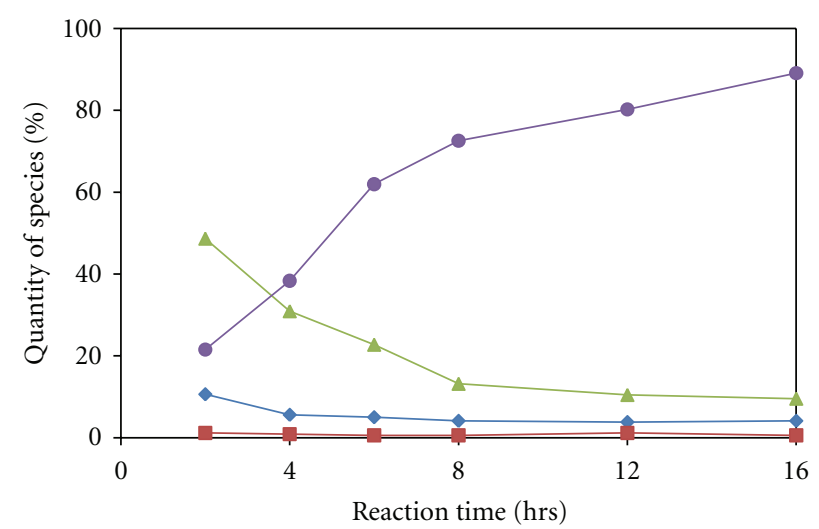

Figure 4: Evolution of the reaction profile for I, cis$\left[\mathrm{Pt}\left({ }^{15} \mathrm{NH}_{3}\right)_{2} \mathrm{I}_{2}\right]$ with the DNA duplex $R, S-5^{\prime}-\mathrm{d}$ (ATATGsGTATA)$3^{\prime} \cdot 5^{\prime}-d($ TATACCATAT $)-3^{\prime}$ containing a single phosphorothioate substitution, recorded as a function of time based on integration of $2 \mathrm{D}\left[{ }^{1} \mathrm{H},{ }^{15} \mathrm{~N}\right] \mathrm{HSQC}$ NMR data acquired at a magnetic field strength of $14.1 \mathrm{~T}\left({ }^{1} \mathrm{H}=600 \mathrm{MHz}\right)$. Key: blue diamond: cis- $\left[\mathrm{Pt}\left({ }^{15} \mathrm{NH}_{3}\right)_{2} \mathrm{I}_{2}\right]$ starting material; red square: cis- $\left[\mathrm{Pt}\left({ }^{15} \mathrm{NH}_{3}\right)_{2} \mathrm{I}\left(\mathrm{OH}_{2}\right)\right]^{+}$monoaqua, monoiodo adduct; green triangle: cis- $\left[\mathrm{Pt}\left({ }^{15} \mathrm{NH}_{3}\right)_{2} \mathrm{I}, \mathrm{S}\right]^{+}$monoiodo, mono-phosphorothioate adduct; violet circle: cis- $\left[\mathrm{Pt}\left({ }^{15} \mathrm{NH}_{3}\right)_{2} \mathrm{~S}, \mathrm{G}^{6}-\right.$ $N 7]^{2+}$ reaction end product.

of RNA [32-35] and exists as unmodified mismatches in DNA in the context of centromeres within chromosomes $[36,37]$. In this study, it was, therefore, considered to be of value to explore the relationship between the reaction of an intact duplex containing a tandem sheared G.A mismatch both in the presence and absence of a phosphorothioate modification.

In contrast to the reaction of $\mathbf{I}$ with the isolated $\mathrm{d}(\mathrm{GpA})$ dimer (III), the reaction of the tandem sheared G. A mismatch duplex VI progressed to end products beyond the initial aquation stage. A second minor monoiodo, mono"oxygen" intermediate formed (see Figure 5 for representative reaction profile) with $\delta\left({ }^{15} \mathrm{~N} /{ }^{1} \mathrm{H}\right)=-47.73 / 4.13\left({ }^{15} \mathrm{~N}\right.$ trans to $\mathrm{I})$ and $-80.54 / 3.65 \mathrm{ppm}\left({ }^{15} \mathrm{~N}\right.$ trans to $\left.\mathrm{O}\right)$, which was proposed to be associated with substitution by oxygen from the phosphodiester backbone (evidence for which also existed in the reaction of $\mathbf{I}$ with the dimer $\mathrm{d}(\mathrm{GpA})$, III). The main intermediate, however, clearly arose from an adduct in which ${ }^{15} \mathrm{~N}$ was trans to both iodide $\left(\delta\left({ }^{15} \mathrm{~N} /{ }^{1} \mathrm{H}\right)\right.$ $=-46.57 / 4.35 \mathrm{ppm}, 22$ in Figure 2(c)) and to nitrogen $\left(\delta\left({ }^{15} \mathrm{~N} /{ }^{1} \mathrm{H}\right)=-75.02 / 4.13\right.$ and $-75.87 / 4.06 \mathrm{ppm}, 23$ and 24 in Figure 2(c)). The intensity associated with cross-peak 22 was twice that of either $\mathbf{2 3}$ or $\mathbf{2 4}$ indicating formation of two similar adducts. The precise nature of these is unknown but speculation can be made that they arise through adduct formation between platinum and G-N7. The presence of three guanine residues in the sequence provides scope for reaction at several centres, and this is the most likely explanation for the formation of at least two sets of cross-peaks in the associated $2 \mathrm{D}\left[{ }^{1} \mathrm{H},{ }^{15} \mathrm{~N}\right]$ HSQC NMR data arising from adducts possessing the structure $c i s-\left[\mathrm{Pt}\left({ }^{15} \mathrm{NH}_{3}\right)_{2} \mathrm{I},\left\{\mathrm{d}\left(\mathbf{V I}-\mathrm{G}^{3}-\right.\right.\right.$ N7) $\}]^{+}$. Evidence for adduct formation at $\mathrm{G}^{3}-N 7$ arose from the $1 \mathrm{D}{ }^{1} \mathrm{H}$ NMR data acquired in an interleaved fashion 


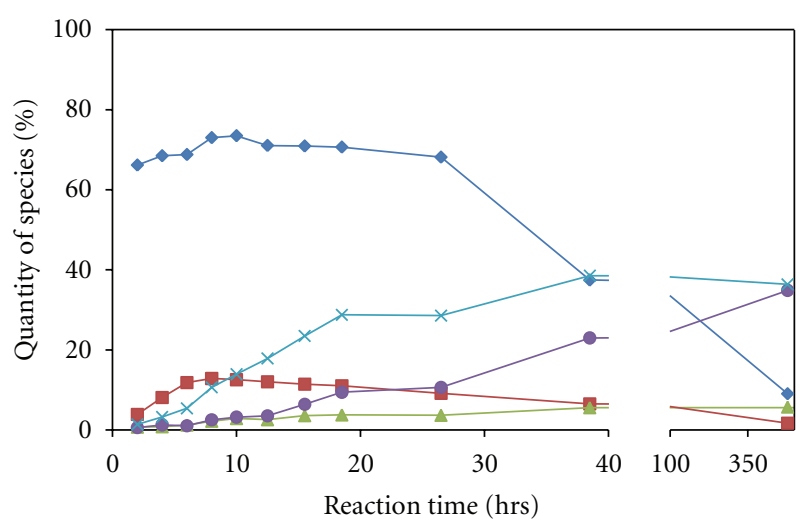

FIGURE 5: Evolution of the reaction profile for I, cis- $\left[\mathrm{Pt}\left({ }^{15} \mathrm{NH}_{3}\right)_{2} \mathrm{I}_{2}\right]$ with the tandem sheared GA mismatch DNA duplex d(GCGAGC) recorded as a function of time based on integration of $2 \mathrm{D}\left[{ }^{1} \mathrm{H},{ }^{15} \mathrm{~N}\right]$ HSQC NMR data acquired at a magnetic field strength of $14.1 \mathrm{~T}\left({ }^{1} \mathrm{H}\right.$ $=600 \mathrm{MHz})$. Key: blue diamond: $c i s-\left[\mathrm{Pt}\left({ }^{15} \mathrm{NH}_{3}\right)_{2} \mathrm{I}_{2}\right]$ starting material; red square: cis- $\left[\mathrm{Pt}\left({ }^{15} \mathrm{NH}_{3}\right)_{2} \mathrm{I}\left(\mathrm{OH}_{2}\right)\right]^{+}$monoaqua, monoiodo adduct; green triangle: minor cis- $\left[\mathrm{Pt}\left({ }^{15} \mathrm{NH}_{3}\right)_{2} \mathrm{I}, \mathrm{O}\right]^{+}$monoiodo, mono-"O" adduct; cyan cross: major cis- $\left[\mathrm{Pt}\left({ }^{15} \mathrm{NH}_{3}\right)_{2} \mathrm{I}, N\right]^{+}$intermediate; violet circle: cis- $\left[\mathrm{Pt}\left({ }^{15} \mathrm{NH}_{3}\right)_{2} \mathrm{~N}, \mathrm{~N}\right]^{2+}$ reaction end product.

between the 2D $\left[{ }^{1} \mathrm{H},{ }^{15} \mathrm{~N}\right]$ HSQC NMR data sets. These data showed gradual loss of the ${ }^{1} \mathrm{H}$ NMR signal assigned to $\mathrm{G}^{3} \mathrm{H} 8\left(\delta^{1} \mathrm{H}=8.23 \mathrm{ppm}\right)$ [30] with simultaneous growth of a signal at $\delta^{1} \mathrm{H}=8.87 \mathrm{ppm}$, typical of G-H8 ${ }^{1} \mathrm{H}$ NMR resonances when platinum is bound at the adjacent $N 7$ centre [21]. This relatively long lived intermediate gradually converted to a bidentate adduct in which ${ }^{15} \mathrm{~N}$ was trans to nitrogen $\left(\delta\left({ }^{15} \mathrm{~N} /{ }^{1} \mathrm{H}\right)=-66.99 / 4.60\right.$ and $-67.71 / 4.46 \mathrm{ppm}$, cross-peaks 25 and 26 in Figure 2(c)). Little opportunity for 1,2-intrastrand cross-link formation occurs in the context of $\mathrm{d}(\mathrm{GCGAGC})_{2}$. Although the presence of the $\mathrm{A}^{4} \mathrm{pG}^{5}$ step exists, which is known to be of lower preference for attack by cisplatin compared with GpG but is nevertheless still reactive towards platinum-based drugs, in this context $\mathrm{A}^{4}$ $N 7$ is not available for bond formation. The sheared nature of the G.A mismatch base pair buries this atom in the core of the double helix. For this reason, it is speculated that the bis-adduct formed as the end product associated with the reaction between $\mathrm{d}(\mathrm{GCGpAGC})_{2}, \mathbf{V I}$, and $\mathbf{I}$ is one in which two adjacent G-N7 atoms on opposite strands are connected to the same platinum centre, that is, preferential formation of a G-N7/G-N7 interstrand cross-link. A structural model showing the feasibility of this is shown (Figure 6) and further discussion follows (vide infra).

In contrast to this and based on the study of the model dimer $\mathrm{d}(\mathrm{GsA})$, IIIs, it was anticipated that attack at the sulphur atom of the phosphorothioate unit in d(GCGsAGC) $)_{2}$, IVs, would occur preferentially and rapidly in the first instance followed by further progress of the reaction to form further end products. Evidence for formation of the reactive monoaqua species existed from the $2 \mathrm{D}\left[{ }^{1} \mathrm{H},{ }^{15} \mathrm{~N}\right]$ HSQC NMR data associated with this reaction, but along with this was detected the formation of a monosulphur, mono-nitrogen species which contrasted significantly with the reaction of dimer $\mathrm{d}(\mathrm{GsA})$, IIIs $\left(\delta\left({ }^{15} \mathrm{~N} /{ }^{1} \mathrm{H}\right)=-44.74 / 4.23\right.$, $-46.26 / 4.22 \mathrm{ppm},{ }^{15} \mathrm{~N}$ trans to $\mathrm{S}, 27$ and 28 in Figure 2(d); $\delta\left({ }^{15} \mathrm{~N} /{ }^{1} \mathrm{H}\right)=-66.99 / 4.16 \mathrm{ppm},{ }^{15} \mathrm{~N}$ trans to $\mathrm{N}, 29$ in Figure $2(\mathrm{~d}))$. These cross-peaks persisted through the course of the reaction, building in intensity throughout. Formation of the monoiodo, monosulphur intermediate was also observed as product accumulated through the course of the reaction $\left(\delta\left({ }^{15} \mathrm{~N} /{ }^{1} \mathrm{H}\right)=-47.64 / 4.06\right.$ and $-54.65 / 4.04 \mathrm{ppm}$, ${ }^{15} \mathrm{~N}$ trans to $\mathrm{S}$ and ${ }^{15} \mathrm{~N}$ trans to I, cross-peaks 30 and 31, resp., in Figure 2(d)). Whilst other N,S adducts evolved over a longer period of time, it was clear that the main end product was represented in the $2 \mathrm{D}\left[{ }^{1} \mathrm{H},{ }^{15} \mathrm{~N}\right]$ HSQC NMR data by the cross-peaks 27-29, two products being most likely formed as a result of the phosphorothioate diastereoisomers. With the reactive $S$ isolated between $\mathrm{G}^{3}$ and $\mathrm{A}^{4}$ in the DNA sequence, the question immediately arises as to which nitrogen centre the platinum attaches to in order to enable formation of a macrochelate to occur, a process which does not take place in the isolated case of the dimer $d(G s A)$, IIIs. The answer lies in the difference between IIIs and VIs being extremely stable duplex formation in the case of the latter for a mismatched duplex. Evidence for the existence of VIs as a stable duplex arose from assessment of chemical shifts as a function of temperature for $\mathrm{d}(\mathrm{GCG} A \mathrm{GCC})_{2}$ compared with $\mathrm{d}(\mathrm{GCGpAGC})_{2}$ for which melting temperatures were determined to be 317 K (See Figure S1 in the Supplementary Material available online at doi: 10.1155/2011/319757) and $321 \mathrm{~K}$ [30], respectively. The phosphodiester backbone in tandem sheared GA mismatch duplex DNA adopts a $\mathrm{B}_{\mathrm{II}}$ conformation rather than the more common $\mathrm{B}_{\mathrm{I}}$ conformation in regular DNA $[34,38]$ which allows accommodation of the unusual sheared mismatch base pairing. In the context of $\mathrm{d}\left(\mathrm{GCGsAG} \mathrm{G}^{5} \mathrm{C}_{2}\right.$, the most obvious candidate for $S, N$ macrochelate formation was from platinum attached to both phosphorothioate sulphur at the GsA step and $G^{5}-N 7$, allowed due to the geometrical arrangement caused by this unusual local topology of the DNA backbone. Thus evidence supports the assertion that formation of the macrochelate cis- $\left[\mathrm{Pt}\left({ }^{15} \mathrm{NH}_{3}\right)_{2} S,\left\{\mathrm{~d}\left(\mathbf{V I s}-\mathrm{G}^{5}-\mathrm{N} 7\right)\right\}\right]^{2+}$ occurs, in which the platinum centre is associated with the $(n+1) 3^{\prime}$-nucleotide in the context $\mathrm{d}\left(\mathrm{G}^{(n-1)} \mathrm{sA}^{(n)} \mathrm{G}^{(n+1)}\right)$ (Figure 7).

\subsubsection{ODNs Containing Central GpT and R,S-GsT Sequences.}

To complete the investigations of the effects of nucleic acid phosphodiester backbone topology on the profile of the reaction under consideration, it was appropriate to examine the context of a molecule which has been reported to have polymorphous behaviour, forming in particular a hairpin loop structure along with random coil and duplex structures. The specific remit in this work was investigation of the difference between the effects on the reaction caused by the presence or absence of the phosphorothioate sulphur at a turning point in the hairpin. Nucleic acid hairpin loops attract a great deal of interest in the scientific literature, forming key structural elements in both reactive DNA and RNA structures including ribozymes and DNAzymes. In case of encountering hairpin loop structures, the question addressed here is how would cisplatin and related drug analogues attach and behave at such geometrically altered 


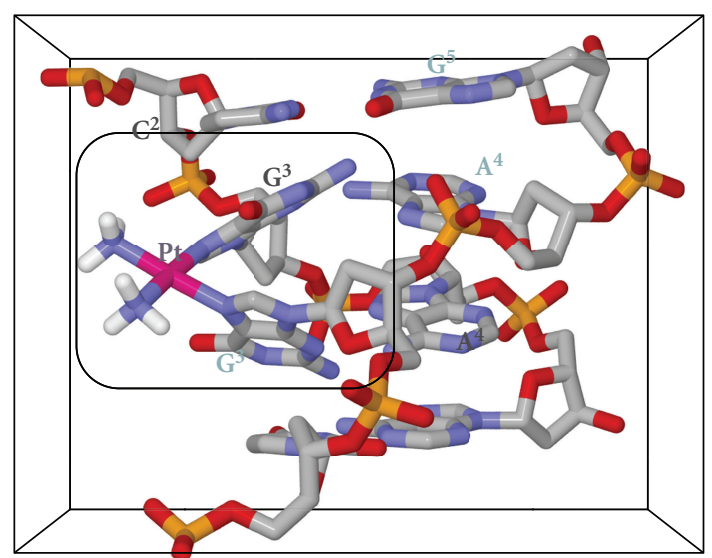

(a)

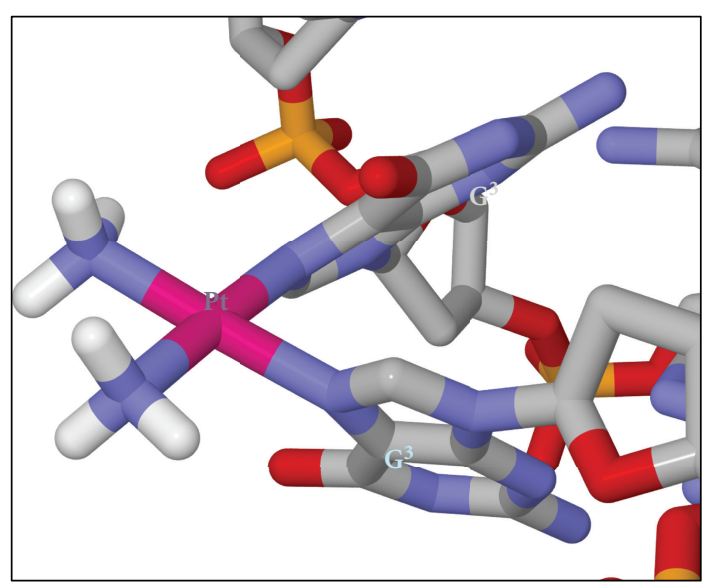

(b)

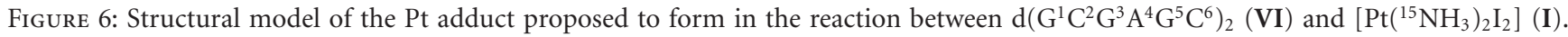
Context for the $\mathrm{G}^{3}-N 7 / \mathrm{G}^{3}-N 7$ interstrand cross-link (a) showing nucleotides associated with different nucleic acid strands labelled by colour coded lettering. Detail (b) of the cis- $\left[\mathrm{Pt}\left({ }^{15} \mathrm{NH}_{3}\right)_{2} \mathrm{G}^{3}-\mathrm{N} 7, \mathrm{G}^{3}-\mathrm{N} 7\right]^{2+}$ interstrand cross-link at the tandem sheared $\mathrm{G} \cdot \mathrm{A}$ mismatch site.

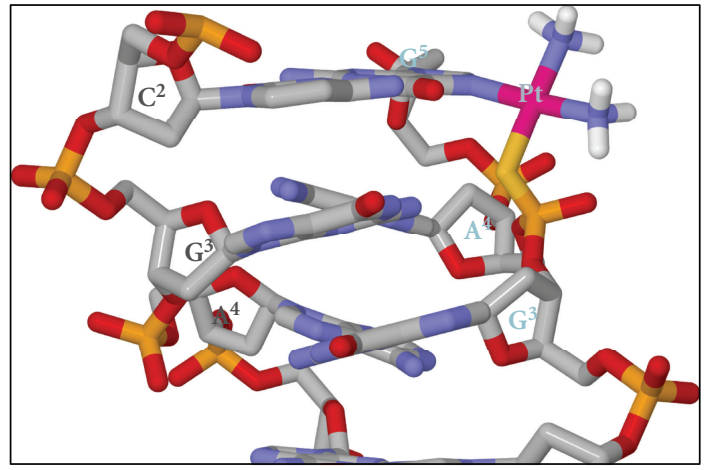

Figure 7: Structural model of the $\mathrm{Pt}$ adduct proposed to form in the reaction between $R, S-\mathrm{d}\left(\mathrm{G}^{1} \mathrm{C}^{2} \mathrm{G}^{3} \mathrm{sA}^{4} \mathrm{G}^{5} \mathrm{C}^{6}\right)_{2}$ (VIs) and $\left[\mathrm{Pt}\left({ }^{15} \mathrm{NH}_{3}\right)_{2} \mathrm{I}_{2}\right]$ (I). ${ }^{\sim}$ Nucleotides associated with different nucleic acid strands are labelled by colour-coded lettering. The platinum centre attached to both phosphorothioate sulphur and $\mathrm{G}^{5}-\mathrm{N} 7$ is indicated by the label Pt.

target sites compared with those of structured duplexes? The sequence chosen for study in this work contained a $\mathrm{d}(\mathrm{GT})$ mismatch unit as the central base step in an octamer nucleic acid sequence, one reported to allow formation of hairpin loops with only two nucleotides [28, 29]. The shortest sequence which would form a hairpin loop under controlled conditions was selected for study, namely, the mismatched sequence d(CGCGpTGCG) VII and its phosphorothioate analogue d(CGCGsTGCG) VIIs. The amorphous behaviour of this sequence is such that ready interconversion occurs between hairpin loop, random coil, and duplex forms. Characteristic resonances appear in the $1 \mathrm{D}{ }^{1} \mathrm{H}$ NMR spectrum of the material, which can be used as markers to determine which components of the three-way equilibrium are present at any one time. Typically at lower concentrations, in the absence of salt, the hairpin form of the structure predominates (Figure 8(a)). In the NMR data recorded immediately following addition of $\mathbf{I}$ to VII, resonances were observed (designated $*$ in Figure 8), which were assigned to an alternative structural form, speculated to be a duplex structure containing G.T mismatched base-pairs. An alternative hairpin loop form also appeared to be present on the basis of the characteristic chemical shift of ${ }^{\dagger} \mathrm{T}^{5} \mathrm{H}_{4}$, and ${ }^{\dagger} \mathrm{T}^{5} \mathrm{CH}_{3}{ }^{1} \mathrm{H}$ NMR resonances, appearing immediately adjacent to the resonances expected for the major hairpin loop form of the structure as reported previously (designated $\mathbf{h}$ in Figure 8). The course of the reaction of VII with I was not well defined by the $1 \mathrm{D}{ }^{1} \mathrm{H}$ NMR data, which can often be the case when monitoring such reactions by NMR spectroscopy and one of the reasons why $2 \mathrm{D}\left[{ }^{1} \mathrm{H},{ }^{15} \mathrm{~N}\right]$ HSQC NMR spectroscopy is more suitable for profiling these types of reaction. However, growth of two resonances over the course of the reaction and assigned to imino protons resonating at $\delta^{1} \mathrm{H}=12.73$ and $13.21 \mathrm{ppm}$ was consistent with a symmetrical octamer duplex in which the terminal base pairs are frayed and the central G.T mismatch does not give rise to a visible imino proton resonance. Therefore, whilst the data were not unambiguous, one may speculate that the end product formed, which gave rise to $2 \mathrm{D}\left[{ }^{1} \mathrm{H},{ }^{15} \mathrm{~N}\right]$ HSQC NMR cross-peaks at $\delta\left({ }^{15} \mathrm{~N} /{ }^{1} \mathrm{H}\right)=$ $-66.57 / 4.51$ and $-67.01 / 4.41 \mathrm{ppm}\left({ }^{15} \mathrm{~N}\right.$ trans to $\mathrm{N}$ in both instances), does so through formation of either a GT or GG cross-link which stabilizes the duplex form of the octamer (Figure 2(e)).

In a similar way, formation of a product which gave rise to two imino proton resonances at $\delta^{1} \mathrm{H}=13.50$ and $13.19 \mathrm{ppm}$, where there was previously only one broad ${ }^{1} \mathrm{H}$ NMR resonance at $\delta^{1} \mathrm{H}=13.19 \mathrm{ppm}$, occurred in the case of the reaction of I with VIIs, d(CGCGsTGCG) (Figure 9). This was considered to be consistent with the formation of a mismatched duplex DNA structure stabilized in some manner by reaction with $\mathbf{I}$. Indeed, the presence of low intensity cross-peaks in the $2 \mathrm{D}\left[{ }^{1} \mathrm{H},{ }^{15} \mathrm{~N}\right]$ HSQC NMR 


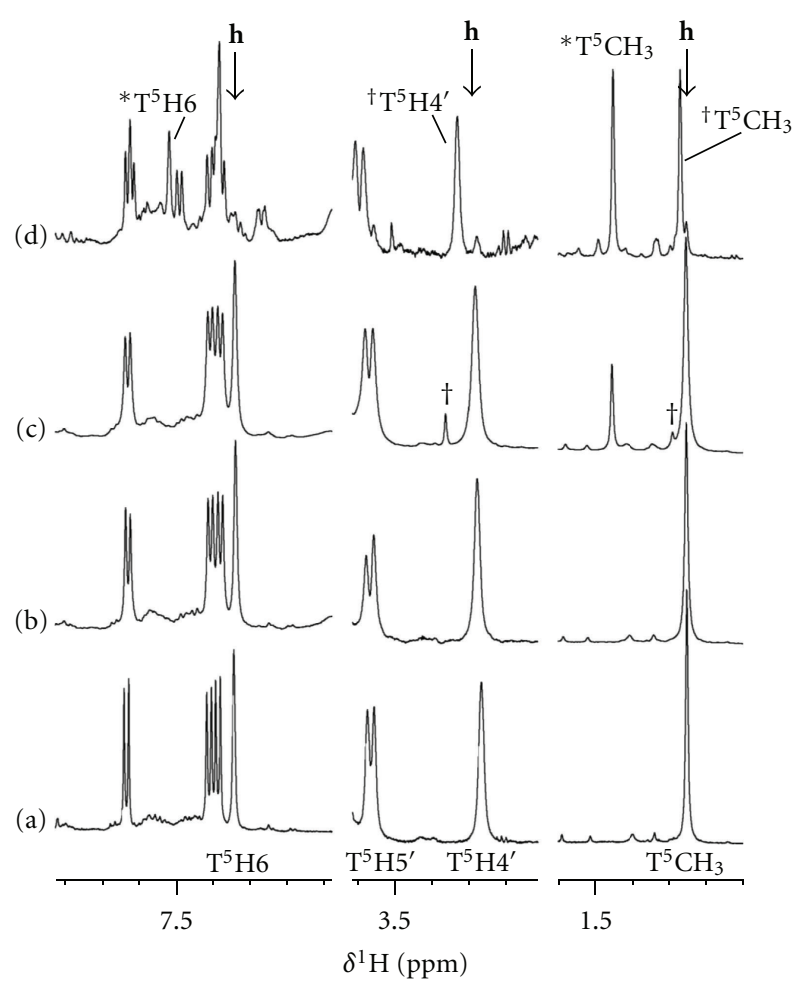

FIGURE 8: Regions of the $1 \mathrm{D}{ }^{1} \mathrm{H}$ NMR spectra of $\mathrm{d}\left(\mathrm{CGCGT}{ }^{5} \mathrm{GCG}\right)$ acquired at $600 \mathrm{MHz}$ showing characteristic resonances associated with the hairpin loop form of the molecule. (a) Unmodified octamer under salt-free condition at a concentration of $1.0 \mathrm{mM}$ [Reference Data] (b) Unmodified octamer immediately prior to the addition of I (c) Unmodified octamer immediately following the addition of I (d) Phosphorothioate modified octamer immediately following the addition of $\mathbf{I}$. " $h$ " indicates the presence of a hairpin form of the octamer. For (c) and (d), additional resonances labelled $*$ were ascribed to an alternative structural form.

spectrum of the reaction between I and VIIs at $\delta\left({ }^{15} \mathrm{~N} /{ }^{1} \mathrm{H}\right)$ $=-66.76 / 4.55$ and $-67.12 / 4.42 \mathrm{ppm}$ (both ${ }^{15} \mathrm{~N}$ trans to $\mathrm{N})$ supported this assertion since these data were virtually identical to the case of VII, d(CGCGpTGCG). However, evidence for more major product formation existed in which ${ }^{15} \mathrm{~N}$ was trans to both $S$ and $N$, suggesting that the major reaction profile involved phosphorothioate sulphur of VIIs and cross-link formation to a nitrogen centre creating the eventual end product. Two methyl resonances for the $\mathrm{T}^{5}$ residue existed in the $1 \mathrm{D}^{1} \mathrm{H}$ NMR spectrum of VIIs in the absence of I. These corresponded to a form of the hairpin structure and most likely the mismatched duplex structure as indicated in Figure 8(d) by ${ }^{*} \mathrm{~T}^{5} \mathrm{CH}_{3}$ and ${ }^{\dagger} \mathrm{T}^{5} \mathrm{CH}_{3}$. Following addition of the reagent, $\mathbf{I}$, new resonances appeared in the $1 \mathrm{D}{ }^{1} \mathrm{H}$ NMR data at $\delta^{1} \mathrm{H}=1.42$ and $1.33 \mathrm{ppm}$, which evolve from intermediates at a rate similar to the evolution of the main intermediates identified from the $2 \mathrm{D}\left[{ }^{1} \mathrm{H},{ }^{15} \mathrm{~N}\right] \mathrm{HSQC}$ NMR data (Figures 10 and 11). The intermediates were diastereoisomers of molecules in which ${ }^{15} \mathrm{~N}$ was trans to iodide $\left(\delta\left({ }^{15} \mathrm{~N} /{ }^{1} \mathrm{H}\right)=-54.49 / 3.94\right.$ (major intermediate); $-55.26 / 3.88 \mathrm{ppm}$ (minor intermediate)) and sulphur $\left(\delta\left({ }^{15} \mathrm{~N} /{ }^{1} \mathrm{H}\right)=-45.87 / 4.07\right.$ (major intermediate); (e)

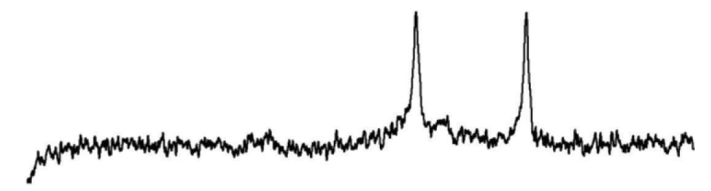

(d)

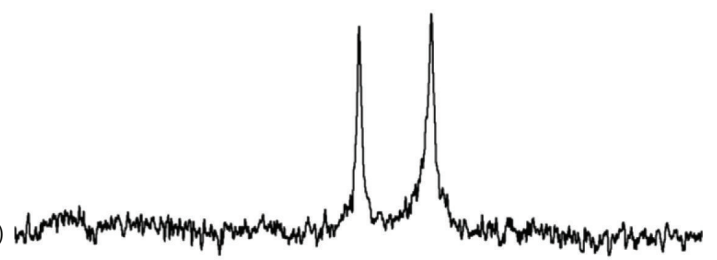

(c)

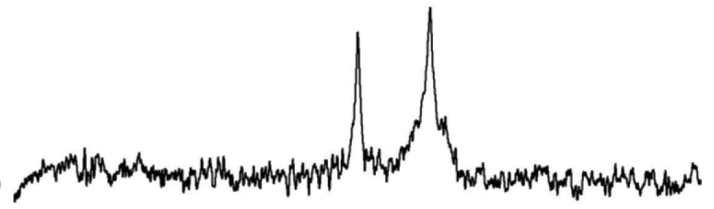

(b)

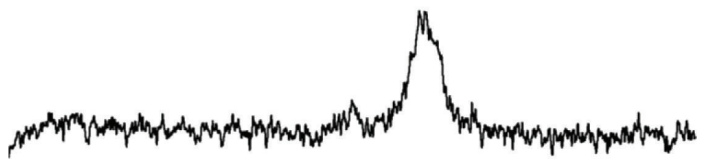

(a)

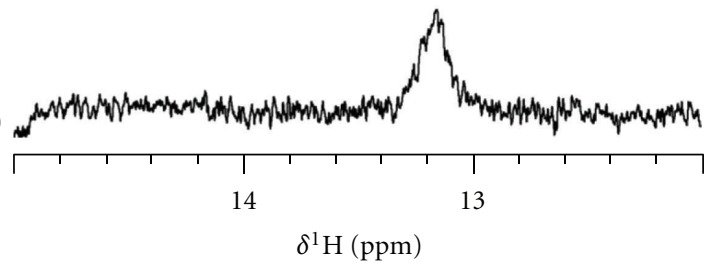

Figure 9: Imino proton resonance region of the $600 \mathrm{MHz} 1 \mathrm{D}$ ${ }^{1} \mathrm{H}$ NMR spectra of the reaction between $\left[\mathrm{Pt}\left({ }^{15} \mathrm{NH}_{3}\right)_{2} \mathrm{I}_{2}\right], \quad I$, and octamer nucleic acids of sequence d(CGCGTGCG). (a)-(d) d(CGCGsTGCGC) with I after (a) 0 hrs; (b) 4 hrs; (c) 14 hrs; (d) 67 hrs. (e) d(CGCGpTGCGC) after 24 hrs.

$-47.78 / 4.09 \mathrm{ppm}$ (minor intermediate)). Since growth and decay of both $2 \mathrm{D}\left[{ }^{1} \mathrm{H},{ }^{15} \mathrm{~N}\right]$ HSQC NMR data and $1 \mathrm{D}$ ${ }^{1} \mathrm{H}$ NMR data associated with the sulphur intermediates occurred at the same rates as one another, it was clear that attachment by cis- $\left[\left\{\mathrm{Pt}\left({ }^{15} \mathrm{NH}_{3}\right)_{2} \mathrm{I}\right\}\right]^{+}$at sulphur influenced the chemical shift of the $\mathrm{T}^{5}$ methyl resonance. Two forms of the intermediate were generated as a result of attachment at two different chiral centres, namely, the $R$ and $S$ forms of the phosphorothioate. Growth of the resonance at $\delta^{1} \mathrm{H}=$ $1.25 \mathrm{ppm}$ corresponded to formation of the hairpin form of the ODN, as represented in Figures $8(\mathrm{a})-8(\mathrm{c})$. Loss of the ${ }^{1} \mathrm{H}$ NMR signal arising from what was proposed to be the $T^{5}$ methyl group of the mismatched duplex d(CGCGsTGCG) 2 suggested that ring closure occurred to create an $S, N$ macrochelate hairpin structure stabilized by the presence of the platinum centre. Thus, a hairpin form of the ODN bound to platinum by means of macrochelate formation preferentially stabilizes hairpin over duplex forms. The exact nature of the structure of the hairpin is currently unknown since it is not completely clear at which nitrogen the platinum is attached. However, comparison with similar data arising from the reaction between dimer $\mathrm{d}(\mathrm{GsT})$ (IVs) and I 


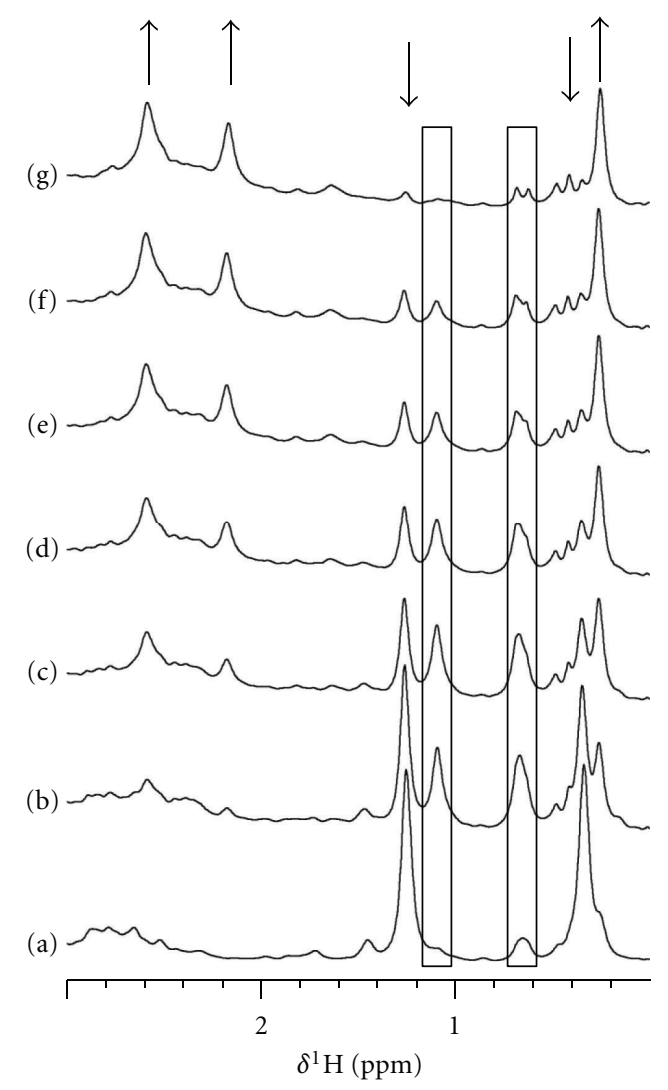

FIGURE 10: Methyl proton resonance region of the $600 \mathrm{MHz} 1 \mathrm{D}$ ${ }^{1} \mathrm{H}$ NMR spectra of the reaction between $\left[\mathrm{Pt}\left({ }^{15} \mathrm{NH}_{3}\right)_{2} \mathrm{I}_{2}\right]$, I, and phosphorothioate octamer ODN d(CGCGsTGCG), VIIs. (a) After $1 \mathrm{hr}$; (b) $5 \mathrm{hrs;} \mathrm{(c)} 9 \mathrm{hrs;} \mathrm{(d)} 13 \mathrm{hrs;} \mathrm{(e)} 17 \mathrm{hrs;} \mathrm{(f)} 21 \mathrm{hrs;} \mathrm{(g)} 68 \mathrm{hrs.}$ Boxed signals: intermediates; downward arrows: starting materials; upward arrows: end products.

(Figures 1(f) and 2(f)) suggested that the presence of a thymine residue $3^{\prime}$ to the phosphorothioate linkage is sufficient to enable ring closure to occur. Thus, it is plausible based on the NMR data that the platinum species present as the end product to this reaction is cis- $\left[\mathrm{Pt}\left({ }^{15} \mathrm{NH}_{3}\right)_{2}\{\mathrm{~S}\right.$, $\mathrm{d}$ (VIIs$\left.\left.\left.\mathrm{T}^{5}-\mathrm{N} 3\right)\right\}\right]^{2+}$. Further data are required to fully confirm this. Modelling studies of such a complex currently indicate that this type of product would be geometrically strained and so further evidence is required to support this notion. Nevertheless, it is clear that such geometry is able to direct the course of reaction as a result of the unusual backbone arrangement in the two-nucleotide hairpin turn. These data are summarized in Table 2.

\section{Discussion}

4.1. GpN Dimers React in Predictable Ways. A substantial amount of research work has taken place to date in which the reactions with cisplatin and its analogues of monomer-, dimer-, and oligo-nucleotides have been investigated. These have been considered to a large degree with a view to understanding reactivity and complex formation in the context of duplex DNA. For DNA sequences of the form

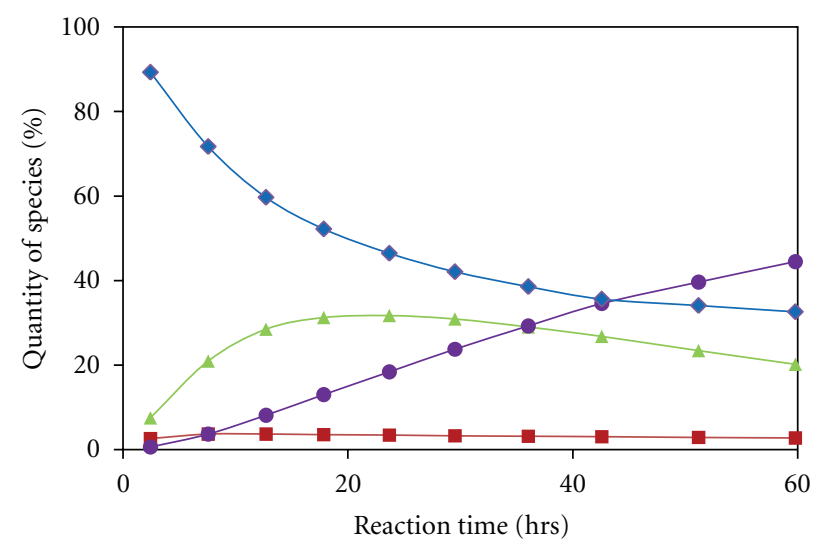

Figure 11: Evolution of starting material, intermediates, and products for the reaction of $\left[\mathrm{Pt}\left({ }^{15} \mathrm{NH}_{3}\right)_{2} \mathrm{I}_{2}\right]$, I, with $R, S$-d(CGCGsTGCG), VIIs based on integration of $2 \mathrm{D}\left[{ }^{1} \mathrm{H},{ }^{15} \mathrm{~N}\right]$ HSQC NMR data. Key: blue diamond: $c i s-\left[\mathrm{Pt}\left({ }^{15} \mathrm{NH}_{3}\right)_{2} \mathrm{I}_{2}\right]$ starting material; red square: cis- $\left[\mathrm{Pt}\left({ }^{15} \mathrm{NH}_{3}\right)_{2} \mathrm{I}\left(\mathrm{OH}_{2}\right)\right]^{+}$monoaqua, monoiodo adduct; green triangle: cis- $\left[\mathrm{Pt}\left({ }^{15} \mathrm{NH}_{3}\right)_{2} \mathrm{I}, \mathrm{S}\right]^{+}$monoiodo, monosulphur adduct; violet circle: cis- $\left[\mathrm{Pt}\left({ }^{15} \mathrm{NH}_{3}\right)_{2} \mathrm{~N}, \mathrm{~S}\right]^{2+}$ reaction end product.

$5^{\prime}-\mathrm{d}(\ldots \mathrm{NNNNPuPuNNNN} .)-.3^{\prime}$, where Pu represents a purine nucleotide (either A, adenosine or G, guanosine), greater initial preference is displayed for reaction at the $3^{\prime}$-purine than at the $5^{\prime}$-purine. Ring closure to form the 1,2-intrastrand cross-link between adjacent residues occurs an order of magnitude faster for $3^{\prime}$-compared with $5^{\prime}$-monosubstituted DNA adducts [26, 27]. Guanine-N7 is more capable of complex formation with the reactive monoaqua species $\left[\mathrm{Pt}\left(\mathrm{NH}_{3}\right)_{2} \mathrm{X}\left(\mathrm{OH}_{2}\right)\right]^{+}(\mathrm{X}=$ halide, either $\mathrm{I}^{-}$or $\left.\mathrm{Cl}^{-}\right)$than adenine-N7. Consequently, adduct formation occurs preferentially in duplex nucleic acids structures when the $3^{\prime}$-purine is guanine. Macrochelate formation occurs in the following stages of the reaction with a greater preponderance for formation of the 1,2-bis adduct with GpG compared with the 1,2-Pt-bis adduct with ApG among other adducts that are formed. In the case of ODNs of sequence

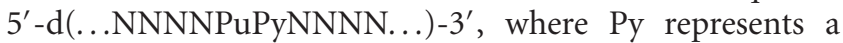
pyrimidine nucleotide (either $\mathrm{C}$, cytosine, or $\mathrm{T}$, thymine), reaction at thymine $\mathrm{N3}$ is known, and in the context $\mathrm{d}(\mathrm{GpT})$, it is not surprising that adduct formation can occur to form monoiodo, mono-nitrogen adducts via platinum attaching at T-N3. This adduct is not further ring closed to form the macrochelate. Thus, in this study, end products are largely anticipated for the dimers. $\mathrm{d}(\mathrm{GpG})$ forms the cis- $\left[\mathrm{Pt}\left({ }^{15} \mathrm{NH}_{3}\right)_{2}\{\mathrm{~d}(\mathrm{II}-\mathrm{G}-\mathrm{N} 7, \mathrm{G}-\mathrm{N} 7)\}\right]^{2+} 1,2$-bis adduct, while $\mathrm{d}(\mathrm{GpA})$ forms a minor quantity of cis- $\left[\mathrm{Pt}\left({ }^{15} \mathrm{NH}_{3}\right)_{2}\{\mathrm{~d}(\mathrm{III}-\right.$ $\mathrm{G}-\mathrm{N} 7, \mathrm{~A}-\mathrm{N} 7)\}]^{2+}$, the majority of the starting material remaining unreacted with evidence existing for aquation to form cis- $\left[\mathrm{Pt}\left({ }^{15} \mathrm{NH}_{3}\right)_{2} \mathrm{I}\left(\mathrm{OH}_{2}\right)\right]^{+}$. $\mathrm{d}(\mathrm{GpT})$ largely forms cis$\left[\mathrm{Pt}\left({ }^{15} \mathrm{NH}_{3}\right)_{2} \mathrm{I}\{\mathrm{d}(\mathrm{IV}-\mathrm{T}-\mathrm{N} 3)\}\right]^{+}$with some evidence existing for minor formation of a cis- $\left[\mathrm{Pt}\left({ }^{15} \mathrm{NH}_{3}\right)_{2} \mathrm{~N}, \mathrm{~N}\right]^{2+}$ adduct, the exact nature of which is currently unknown.

4.2. GsN Dimers React to Form Different Adducts. Based on former precedent [14], reaction of the equivalent dimers, in which the nucleotide-bridging phosphodiester was replaced 
TABLE 2: ${ }^{15} \mathrm{~N} /{ }^{1} \mathrm{H}$ chemical shifts of $2 \mathrm{D}\left[{ }^{1} \mathrm{H},{ }^{15} \mathrm{~N}\right]$ HSQC NMR cross-peaks for the reactions of oligonucleotides with $\left[\mathrm{Pt}\left({ }^{15} \mathrm{NH}\right)_{3} \mathrm{I}_{2}\right]$.

\begin{tabular}{|c|c|c|c|c|c|}
\hline Sample & Code & Complex & Peak & $\delta\left({ }^{15} \mathrm{~N} /{ }^{1} \mathrm{H}\right)$ & ${ }^{15} \mathrm{~N}$ trans to \\
\hline \multirow[t]{4}{*}{ "GpG" decamer } & $\mathrm{V}$ & cis- $\left[\mathrm{Pt}\left({ }^{15} \mathrm{NH}_{3}\right)_{2} \mathrm{I}\left\{\mathrm{d}\left(\mathbf{V}-\mathrm{G}^{6}-\mathrm{N} 7\right)\right\}\right]^{+}$ & 15 & $-47.43 / 4.39$ & $\mathrm{I}$ \\
\hline & & & 16 & $-75.56 / 4.02$ & $\mathrm{~N}$ \\
\hline & & cis- $\left[\mathrm{Pt}\left({ }^{15} \mathrm{NH}_{3}\right)_{2}\left\{\mathrm{~d}\left(\mathbf{V}-\mathrm{G}^{5}-\mathrm{N} 7, \mathrm{G}^{6}-\mathrm{N} 7\right)\right\}\right]^{2+}$ & 17 & $-67.49 / 4.59$ & $\mathrm{~N}$ \\
\hline & & & 18 & $-68.68 / 4.52$ & $\mathrm{~N}$ \\
\hline \multirow[t]{4}{*}{ “GsG” duplex } & Vs & $R$ or $S$ cis- $\left[\mathrm{Pt}\left({ }^{15} \mathrm{NH}_{3}\right)_{2} \mathrm{I}\{\mathrm{d}(\mathbf{V s}-S)\}\right]^{+}$ & 19 & $-46.76 / 4.13$ & S \\
\hline & & & $21^{\dagger}$ & $-54.35 / 3.92$ & I \\
\hline & & $S$ or $R$ cis- $\left[\mathrm{Pt}\left({ }^{15} \mathrm{NH}_{3}\right)_{2} \mathrm{I}\{\mathrm{d}(\mathbf{V s}-S)\}\right]^{+}$ & 20 & $-46.30 / 4.10$ & S \\
\hline & & & $21^{\dagger}$ & $-54.35 / 3.92$ & I \\
\hline \multirow[t]{6}{*}{ “GpA" duplex } & VI & cis- $\left[\mathrm{Pt}\left({ }^{15} \mathrm{NH}_{3}\right)_{2} \mathrm{I}\left\{\mathrm{d}\left(\mathrm{VI}-\mathrm{G}^{3}-\mathrm{N} 7\right)\right\}\right]^{+}$ & 22 & $-46.57 / 4.35$ & I \\
\hline & & & 23 & $-75.02 / 4.13$ & $\mathrm{~N}$ \\
\hline & & cis- $\left[\mathrm{Pt}\left({ }^{15} \mathrm{NH}_{3}\right)_{2} \mathrm{I}\left\{\mathrm{d}\left(\mathrm{VI}-\mathrm{G}^{3}-\mathrm{N} 7\right)\right\}\right]^{+}$ & 22 & $-46.57 / 4.35$ & I \\
\hline & & & 24 & $-75.87 / 4.06$ & $\mathrm{~N}$ \\
\hline & & cis- $\left[\mathrm{Pt}\left({ }^{15} \mathrm{NH}_{3}\right)_{2}\left\{\mathrm{~d}\left(\mathbf{V I}-\mathrm{G}^{3}-\mathrm{N} 7, \mathrm{G}^{3}-\mathrm{N} 7\right)\right\}\right]^{2+}$ & 25 & $-66.99 / 4.60$ & $\mathrm{~N}$ \\
\hline & & & 26 & $-67.71 / 4.46$ & $\mathrm{~N}$ \\
\hline \multirow[t]{6}{*}{ "GsA" duplex } & VIs & $R$ or $S$ cis- $\left[\mathrm{Pt}\left({ }^{15} \mathrm{NH}_{3}\right)_{2} S,\left\{\mathrm{~d}\left(\mathbf{V I s}-\mathrm{G}^{5}-\mathrm{N} 7\right)\right\}\right]^{2+}$ & 27 & $-44.74 / 4.23$ & $\mathrm{~S}$ \\
\hline & & & $29^{\dagger}$ & $-66.99 / 4.16$ & $\mathrm{~N}$ \\
\hline & & $S$ or $R$ cis- $\left[\mathrm{Pt}\left({ }^{15} \mathrm{NH}_{3}\right)_{2} S,\left\{\mathrm{~d}\left(\mathbf{V I s}-\mathrm{G}^{5}-\mathrm{N} 7\right)\right\}\right]^{2+}$ & 28 & $-46.26 / 4.22$ & $\mathrm{~S}$ \\
\hline & & & $29^{\dagger}$ & $-66.99 / 4.16$ & $\mathrm{~N}$ \\
\hline & & cis- $\left[\mathrm{Pt}\left({ }^{15} \mathrm{NH}_{3}\right)_{2} \mathrm{I}\{\mathrm{d}(\mathbf{V I s}-S)\}\right]^{+}$ & 30 & $-47.64 / 4.06$ & S \\
\hline & & & 31 & $-54.65 / 4.04$ & I \\
\hline \multirow[t]{2}{*}{ “GpT” octamer } & VII & cis- $\left[\mathrm{Pt}\left({ }^{15} \mathrm{NH}_{3}\right)_{2}-\mathrm{N}, \mathrm{N}\right]^{2+}$ & - & $-66.57 / 4.51$ & $\mathrm{~N}$ \\
\hline & & & - & $-67.01 / 4.41$ & $\mathrm{~N}$ \\
\hline \multirow[t]{10}{*}{ “GsT” octamer } & VIIs & cis- $\left\{\mathrm{Pt}\left({ }^{15} \mathrm{NH}_{3}\right)_{2}-\mathrm{N}, \mathrm{N}\right\}^{2+}$ & - & $-66.76 / 4.55$ & $\mathrm{~N}$ \\
\hline & & & - & $-67.12 / 4.42$ & $\mathrm{~N}$ \\
\hline & & cis- $\left\{\mathrm{Pt}\left({ }^{15} \mathrm{NH}_{3}\right)_{2}-I, \mathrm{~S}\right\}^{+}$major & & $-54.49 / 3.94$ & I \\
\hline & & & & $-45.87 / 4.07$ & S \\
\hline & & cis- $\left\{\mathrm{Pt}\left({ }^{15} \mathrm{NH}_{3}\right)_{2}-I, \mathrm{~S}\right\}^{+}$minor & & $-55.26 / 3.88$ & I \\
\hline & & & & $-47.78 / 4.09$ & $\mathrm{~S}$ \\
\hline & & $R$ or $S$ cis $-\left[\mathrm{Pt}\left({ }^{15} \mathrm{NH}_{3}\right)_{2}\left\{S, \mathrm{~d}\left(\text { VIIs }-\mathrm{T}^{5}-\mathrm{N} 3\right)\right\}\right]^{2+}$ & - & $-46.77 / 4.44$ & $\mathrm{~S}$ \\
\hline & & & - & $-67.05 / 4.19$ & $\mathrm{~N}$ \\
\hline & & $S$ or $R$ cis- $\left[\mathrm{Pt}\left({ }^{15} \mathrm{NH}_{3}\right)_{2}\left\{S, \mathrm{~d}\left(\text { VIIs- } \mathrm{T}^{5}-\mathrm{N} 3\right)\right\}\right]^{2+}$ & - & $-46.34 / 4.35$ & S \\
\hline & & & - & $-66.12 / 4.18$ & $\mathrm{~N}$ \\
\hline
\end{tabular}

${ }^{\dagger}$ Overlapping peaks.

with $R, S$-phosphorothioate, was anticipated to occur rapidly at the sulphur. The question of which end product would subsequently form in each case was the main focus and reason for examining the reaction of $\left[\mathrm{Pt}\left(\mathrm{NH}_{3}\right)_{2} \mathrm{I}_{2}\right]$ with each of the phosphorothioate dimer analogues in this work as a prelude to exploring the additional influence imposed by topology in well-defined nucleic acid structures. Previous results had shown that for the monomer guanosine- $5^{\prime}$ $O$-(2-thiophosphate) [GDP- $\beta$-S] rapid formation of the monosulphur adduct was quickly followed by formation of the end product macrochelate cis- $\left[\mathrm{Pt}\left(\mathrm{NH}_{3}\right)_{2}(\mathrm{GDP}-\beta-\mathrm{S})\right.$ $N 7, S]$ for which the sugar ring was shown to possess an altered $\mathrm{C}^{\prime}$-endo geometry [14]. Indications from reactions with $5^{\prime}-\mathrm{d}$ (TATGsGCCATA)-3' suggested that enough flexibility existed within the duplex structure to form similar macrochelates but it was not known how a free and substantially less structured dimer would respond to the same reaction conditions. As shown for $R, S-\mathrm{d}(\mathrm{GsG})$, however, it was clear that very rapid reaction occurred at the phosphorothioate sulphur followed largely by ring closure at the $3^{\prime}-\mathrm{G}-\mathrm{N} 7$ to form the cis- $\left[\mathrm{Pt}\left(\mathrm{NH}_{3}\right)_{2}\{\mathrm{~d}(\mathrm{IIs}-\right.$ GsG) $\}-S, N 7]^{2+}$ macrochelate (Figure 1(b), cross-peaks 5 and 6) with some minor 1,2-bis-N7,N7 adduct forming in the same manner as for $d(\mathrm{GpG})$. Since no evidence existed for the formation of a mono-G-N7, monoiodo species through the course of this reaction due to complete reaction of the platinum salt to form the monosulphur adduct, one can speculate that formation of the 1,2-bis-N7,N7 adduct occurs by migration of the Pt-S bond from the $S, N$ macrochelate to form a second Pt-N7 bond with the $5^{\prime}-\mathrm{G}$ residue. This was beyond the scope of the current work but will be of some value to explore in due course.

Since it had been shown clearly that reaction to form any kind of $\mathrm{d}(\mathrm{GpA})$ adduct was at best very slow, it should not have come as a surprise to discover that $\mathrm{d}(\mathrm{GsA})$ would not progress to form a macrochelate end product. However, the 
reality of virtually exclusive formation of the monosulphur, monoiodo adduct $c i s-\left[\mathrm{Pt}\left({ }^{15} \mathrm{NH}_{3}\right)_{2} \mathrm{I}\{\mathrm{d}(\text { IIIs-GsA)-S }\}]^{+}\right.$in the reaction with $\mathrm{d}(\mathrm{GsA})$ was nevertheless surprising. The point concerning relative reactivity of A-N7 versus G-N7 is driven home in this instance and provides an interesting and important point of differentiation for these reactions. In the context of aiming to investigate the reaction with a tandem sheared G. A mismatched duplex structure, the focus in this work was to study reactions in which the $5^{\prime}$-base was guanine in the context $\mathrm{d}(\ldots \mathrm{GN} .$.$) where \mathrm{N}$ in this instance is adenosine. However, in view of this, it would be of value to compare and contrast the reactions of both $\mathrm{d}(\mathrm{GsA})$ and $\mathrm{d}(\mathrm{AsG})$ dimers, a work on which we will report in due course. Further surprise, therefore, ensued when the reaction of "GsA" was monitored in the context of the stable tandem sheared G.A mismatched duplex d(GCGsAGC) $)_{2}$, VIs, and was found to form end products that involved $N, S$ macrochelate formation unlike the case for the dimer $\mathrm{d}(\mathrm{GsA})$. Hence it is clear that topology plays a significant role in the course with which reaction profiles for $\mathrm{d}(\mathrm{GsA})$ compared with $\mathrm{d}$ (GCGsAGC) proceed.

It was equally surprising to observe formation of the $S, N$ macrochelate in the case of $\mathrm{d}(\mathrm{GsT})$, IVs, when reacted with $\left[\mathrm{Pt}\left({ }^{15} \mathrm{NH}_{3}\right)_{2} \mathrm{I}_{2}\right]$. Since it was known from reactions with $\mathrm{d}(\mathrm{GpA})$ and with $\mathrm{d}(\mathrm{GsA})$ (this work) and from the literature precedent that $\mathrm{Pu}=\mathrm{G}$ in the context $5^{\prime}$ -

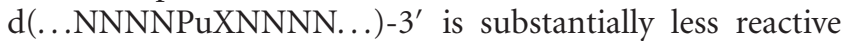
than when $X=G$ in a duplex context, it was clear that the $S, N$ macrochelate reaction product associated with $\mathrm{d}(\mathrm{GsT})$ would most likely arise from macrochelation involving a nitrogen centre from the thymidine residue. The only opportunity for this to occur is via reaction at TN3, which is possible provided that thymine adopts a syn orientation with respect to the sugar in order to present the $\mathrm{N} 3$ atom to a platinum centre that is already attached to the phosphorothioate group (Figure 12). By accommodating macrochelate formation in this way, it still remains possible for base stacking to occur between the thymine residue and neighbouring bases which would thus stabilize any resulting structure. Given the commonality which exists between the NMR data observed for the reaction between I and $\mathrm{d}(\mathrm{GsT})$, IVs, and between I and VIIs, it is intriguing to suggest that stabilization of a hairpin-loop-type structure may be possible through syn orientation of the base $3^{\prime}$ to the phosphorothioate group by formation of the S,T-N3 macrochelate.

4.3.ODNs Form Structure-Specific Adducts with [Pt $\left.\left(\mathrm{NH}_{3}\right)_{2} \mathrm{I}_{2}\right]$. From previous work, it was clear that in the context of a standard B-DNA duplex geometry, formation of either 1,2(G-N7,G-N7) bis adducts or $S, N$ macrochelates was possible on reaction with $\left[\mathrm{Pt}\left(\mathrm{NH}_{3}\right)_{2} \mathrm{I}_{2}\right]$ [14]. In the former case, this cross-link predominates when the DNA phosphodiester backbone is unmodified. In the latter case, reaction at sulphur is very rapid and favoured, with ring closure taking place to form the $S, N$ macrochelate in preference to formation of the 1,2 bis adduct $\left[\mathrm{Pt}\left(\mathrm{NH}_{3}\right)_{2} \mathrm{N7}, \mathrm{N7}\right]^{2+}$. The product of these reactions appears to be the same whether single-stranded DNA or duplex DNA is used. In the case of

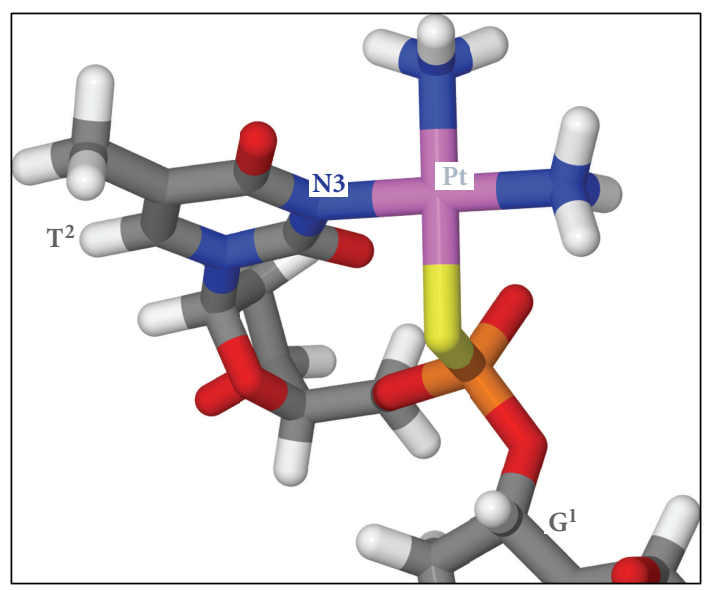

FIgure 12: Model of the proposed structure for the $S, N$ macrochelate cis- $\left[\mathrm{Pt}\left(\mathrm{NH}_{3}\right)_{2}\{\mathrm{~d}(\mathrm{GsT})\}-S, \mathrm{~T}-\mathrm{N} 3\right]^{2+}$ formed from the reaction of $\left[\mathrm{Pt}\left(\mathrm{NH}_{3}\right)_{2} \mathrm{I}_{2}\right]$ with $R, S$-d $(\mathrm{GsT})$, IVs, in which the $3^{\prime}$-residue, $\mathrm{T}^{2}$, is orientated syn with respect to the DNA sugar ring to which it is attached to allow presentation of $\mathrm{N} 3$ for binding to Pt.

duplex DNA, the reaction rates are likely to be enhanced for $S, N$ macrochelate formation since the geometry is restricted and alignment exists for formation of the Pt-N7 bond to the base lying $3^{\prime}$ to the phosphorothioate modification site. The case of a single instance of "GsG" modification in a duplex setting, Vs, (Figure 2(b)) simplifies the interpretation of the data compared with the previously reported instance of the same reaction with d(TATGsGCCATA) [14], which is capable of forming $R, R, S, S$, and $R, S$ duplexes and many resulting product variations on reaction with $\left[\mathrm{Pt}\left(\mathrm{NH}_{3}\right)_{2} \mathrm{I}_{2}\right]$. In contrast, Vs, R,S-d(ATATGsGTATA)-d(TATACCATAT), may form a duplex in which one strand is either $R$ or $S$ at the phosphorothioate centre, thereby reducing the number of potential $S, N$ macrochelate products to two. This was reflected in this work by the clarity of data acquired (Figure 2(b)), which indicated the presence of two sets of cross-peaks arising from two anticipated diastereomeric end products formed during the course of the reaction with $\left[\mathrm{Pt}\left({ }^{15} \mathrm{NH}_{3}\right)_{2} \mathrm{I}_{2}\right]$.

4.4. Tandem Sheared G.A Mismatch Duplexes Form Unprecedented Adducts with $\mathrm{Pt}^{\mathrm{II}}$. The intriguing case in this work arises from reactions with the phosphodiester and singlepoint modification, phosphorothioate-containing ODNs of sequence $\mathrm{d}(\mathrm{GCGAGC})$. This sequence is known to form highly stabilized duplex structures despite its short length as a result of the tandem sheared G.A mismatch located at the centre of the sequence. The sheared nature of the central base pairs places $G^{3}$ of one strand on top of $G^{3}$ in the opposing strand and $\mathrm{A}^{4}$ of one strand stacked on top of $\mathrm{A}^{4}$ on the opposing strand. This type of interaction can almost be considered to be a form of intercalation and results in interlacing or zippering of the two strands at this point with substantial stabilization by $\pi-\pi$ stacking interactions between bases located on opposite strands from one another. Such interactions are additional to those sets of hydrogen bonds 
normally found for self-assembled systems such as DNA and which normally hold two strands together in the form of a duplex.

In the case of $\mathrm{d}(\mathrm{GCGpAGC})_{2}, \mathbf{V I}$, and in contrast to $\mathrm{d}(\mathrm{GpA}), \mathbf{I I I}$, a Pt adduct forms in which two nitrogen centres are trans to each ammine group attached in a cis arrangement to the platinum centre. Since G-N7 is present and accessible to the platinum at the tandem sheared $\mathrm{G} \cdot \mathrm{A}$ mismatch site and since no other nitrogen centres are available for crosslinking purposes throughout the rest of the sequence, the most plausible and obvious explanation for the appearance of two cross-peaks fitting the profile of ${ }^{15} \mathrm{~N}$ trans to nitrogen is via interstrand cross-link formation between the two stacked guanine residues at the mismatch site (Figures 2(c) and 6). The platinum lesion in this instance is one in which the two attached guanine bases are, therefore, orientated head-to-tail with respect to one another in contrast to the usual head-to-head orientation for intrastrand 1,2 crosslinks. The fact that this lesion is able to form is relevant from the point of view of the occurrence of tandem sheared $\mathrm{G} \cdot \mathrm{A}$ mismatches in key locations within biological settings. In spite of the strength with which a tandem sheared $\mathrm{G} \cdot \mathrm{A}$ mismatch duplex is held together through the additional bonding energy associated with $\pi-\pi$ stacking interactions, the presence of such a platinum lesion would effectively covalently tie the two strands together. In the context of gene expression or cell division, such a lesion would put up a considerable barrier to DNA strand separation and is therefore worthy of further investigation in the context of drug discovery. In this work, our focus has rested on examining the reaction profiles associated with such unusual geometries in the presence of cisplatin-type molecules but more detailed work is required to fully characterize the structures of these lesions in detail, which will be reported in due course.

In a fascinating corollary to these findings, the reaction of VIs, $R, S-\mathrm{d}(\mathrm{GCG} A \mathrm{AGC})_{2}$, also forming a stable tandem sheared G.A mismatched duplex structure, was shown to produce a second unprecedented end product which was intrastrand in nature (Figures 2(d) and 7). The DNA backbone at the GpA step in a tandem sheared G.A mismatch unit adopts the more unusual $\mathrm{B}_{\mathrm{II}}$ conformation in which torsion angles $\varepsilon\left(\mathrm{C}^{\prime}-\mathrm{C}^{\prime}-\mathrm{O}^{\prime}-\mathrm{P}\right)$ and $\zeta\left(\mathrm{C}^{\prime}-\mathrm{O}^{\prime}-\mathrm{P}-\mathrm{O} 5^{\prime}\right)$ take the values $-60^{\circ}$ and $180^{\circ}$ (-gauche, trans) compared with the more usual $\mathrm{B}_{\mathrm{I}}$ conformation adopted by the regular B-DNA phosphodiester backbone in which $\varepsilon$ and $\zeta$ take the values $180^{\circ}$ and $-60^{\circ}$ (trans, -gauche), respectively. The upshot of this is that the backbone is locked in position in such a way that platinum, when attached to a phosphorothioate sulphur, is able to bind to the N7 of the guanine base associated with the residue located $3^{\prime}$ in sequence to the G.A mismatch site. With platinum attached to the backbone, no other nitrogen centre is near enough to be able to react with the remaining platinum coordination site except for $\mathrm{G}^{5}-\mathrm{N7}$ in the context of $\mathrm{d}\left(\mathrm{GCGsAG} \mathrm{C}^{5} \mathrm{C}\right)_{2}$. Whereas no reaction beyond formation of the mono- $S$, mono- $I$ adduct occurred in the case of the $\mathrm{d}(\mathrm{GsA})$ dimer, favourable and rapid formation of the $\left[\mathrm{Pt}\left({ }^{15} \mathrm{NH}_{3}\right)_{2}\{\mathrm{~d}(\mathrm{VIs}-\right.$ Gs $\mathrm{AG}-\underline{N 7})\}-S, N 7]^{2+}$ macrochelate occurs for VIs. Since $\mathrm{A}^{4}$ -
$N 7$ is both less reactive toward platinum than G-N7 and at the same time remains inaccessible due to the sheared nature of the G.A base pair, causing the nitrogen to be buried in the core of the duplex, the only option left is formation of the $(n+1)$ adduct. This also explains why the model dimer reaction with $\mathrm{d}(\mathrm{GsA})$ stops at formation of the mono$S$, mono- $I$ adduct. If $\mathrm{d}(\mathrm{GsA})$ self-assembles in solution in a similar manner to that observed in stable duplexes such as VI and VIs, no other centres are available with which the second coordination site of Pt may interact, and for this reason the reaction, as shown in this work (Figure $1(d)$ ), will stop following monosubstitution, in this case at a sulphur site. Interestingly, for the duplex d(GCGsAGC $)_{2}$ immediate loss of the proton NMR signal at $10.35 \mathrm{ppm}$ assigned to $\mathrm{G}^{3} \mathrm{H} 1$ occurred upon addition of $\left[\mathrm{Pt}\left({ }^{15} \mathrm{NH}_{3}\right)_{2} \mathrm{I}_{2}\right]$. Only slight disruption of the structure is required for this proton to undergo more rapid exchange with its surroundings (bulk water) since it is not securely hydrogen bonded due to the sheared nature of the G.A base pair, and this is clearly what immediately happens, coinciding with rapid formation of the monosulphur adduct located in close proximity to imino proton $\mathrm{G}^{3}-\mathrm{H} 1$. Both $R$ and $S$ forms of $\mathrm{d}$ (GCGsAGC) exist in solution resulting in several possible combinations of strands and most likely resulting in a mixture of products substituted with either one or two platinum centres per duplex. This explains the appearance of several sets of peaks in the $2 \mathrm{D}$ $\left[{ }^{1} \mathrm{H},{ }^{15} \mathrm{~N}\right]$ HSQC NMR data used to monitor the reaction between I and VIs. Ongoing work is taking place in relation to understanding more about this structure and detailed studies and analysis of this unusual adduct will be reported in due course.

4.5. A Hairpin Structure Is Stabilized through Adduct Formation with $\mathrm{Pt}^{I I}$. In order to complete an assessment of the effect of backbone geometry and overall structural topology of backbone modified and unmodified nucleic acids on the course of their reaction with $\left[\mathrm{Pt}\left({ }^{15} \mathrm{NH}_{3}\right)_{2} \mathrm{I}_{2}\right]$, the hairpin structure was considered. Backbone modification took place at the position associated with the sequence known to form a turn with only two nucleic acid residues, namely, d(CGTG). The actual sequence used, $\mathrm{d}($ CGCGxTGCG), VII and VIIs, where $\mathrm{x}$ represents phosphate (p) or phosphorothioate (s), is stabilized in the stem region by standard Watson-Crick base pairing. The geometry associated with this sequence is amorphous due to the ease with which it may also form a mismatched duplex structure. By controlling the conditions under which the molecule is studied, the hairpin form may predominate [29]. However, as shown (Figure 8), achieving a pure geometrical form is unpredictable and whilst the hairpin clearly predominates in the case of the structure with the phosphodiester backbone (VII, Figures $8(\mathrm{a})$ and $8(\mathrm{~b})$ ), formation of alternative structures occurred readily with the addition of new salts to the solution (Figure 8(c)). Interestingly, stabilization of a duplex form of the molecule appears to take precedence upon reaction with $\left[\mathrm{Pt}\left({ }^{15} \mathrm{NH}_{3}\right)_{2} \mathrm{I}_{2}\right]$ based on data associated with the imino proton resonance region of the $1 \mathrm{D}{ }^{1} \mathrm{H}$ NMR spectrum (Figure 9). This 
also occurred for VIIs but was accompanied by an additional process which clearly evolved smoothly over time (Figures 10 and 11). 2D $\left[{ }^{1} \mathrm{H},{ }^{15} \mathrm{~N}\right]$ HSQC NMR data (Figure 2(f)) and the associated $1 \mathrm{D}{ }^{1} \mathrm{H}$ NMR data (Figure 10) show that the species formed is hairpin-like with ${ }^{15} \mathrm{~N}$ trans to both $\mathrm{N}$ and $\mathrm{S}$, that is, a phosphorothioate adduct. A similar reaction profile is observed with dimer $\mathrm{d}(\mathrm{GsT})$, IVs, and it is therefore convincing that formation of a hairpin loop structure occurs in which platinum is bound to both phosphorothioate sulphur and to the $\mathrm{T}^{5}-\mathrm{N} 3$ centre, thereby creating an eleven membered ring macrocycle. Many conformational possibilities exist which the $\mathrm{T}^{5}$ residue could adopt with respect to the rest of the nucleic acid structure. However, chemical shift information indicates that the resulting platinum macrochelate adduct appears to adopt a very similar conformation to that of the regular hairpin loop without platinum present. Further investigation of the phenomenon associated with this reaction is in progress, but it is clear from the data presented in this work that adduct formation is able to stabilize a hairpin form. Two intermediates are formed in the reaction whose methyl chemical shifts differ from those of either the end product or the starting materials (Figure 10). Additional peaks present in the data indicate that other reaction processes take place. Investigation of these lies beyond the scope of the current paper but the meaning of these data are in the process of being explored and further work on this will be reported in a proceeding article.

4.6. Potential for New Modes of Drug Delivery. What is clear from these initial studies is that unusual nucleic acid topologies result in different reaction profiles to those expected in the presence of cisplatin-type molecules. In the context of understanding the manner by which platinum drugs might interact with alternative geometry, unmodified nucleic acids as well as in terms of pursuing alternative means of delivering drugs to their targets, these studies are of value and present new structural insights into the reactivity of platinum(II) with nucleic acids. In recent years, a great deal of work has been carried out in attempting to formulate and test different strategies for targeted drug delivery. The antisense approach [39], which may utilize short fragment phosphorothioate antisense ODNs (PS-ODNs), resulted in a number of clinical trials focussed on their therapeutic use [40] and in the commercialization of the first PS-ODN under the name Vitravene in the late 1990s for use against the condition cytomegalovirus retinitis although the drug has since been discontinued [41]. The benefit of phosphorothioate ODNs is their resistance to attack by nucleases enabling them to penetrate the cell nucleus. Combination drug therapy by coadministration of reactive molecules such as those based on cisplatin along with phosphorothioate ODNs may add a new dimension to the use of metals in medicine. The recent focus of attention on the use of photoactivatable platinum prodrugs is particularly appealing. Extending the concept to combined delivery of phosphorothioate targeting ODNs which could be activated and made available by means of UV [42] or red-light irradiation [43, 44] alongside the light activation of a platinum(IV) prodrug using a different wavelength of light would allow location-specific control of DNA binding to occur by means of an antisense mechanism followed by colocation of the activated prodrug in the form of a platinum(II-) sulphur adduct. As shown in this work, cross-linking at key sites such as the tandem sheared G.A mismatch or at loop locations could result in irreparable lesions leading to cytotoxic effects, cell death, and potential therapeutic benefits.

\section{Conclusions}

The work presented in this paper extends the understanding of the manner by which platinum(II) molecules interact with standard phosphodiester and modified phosphorothioate nucleic acids by exploring their reaction with $\left[\mathrm{Pt}\left({ }^{15} \mathrm{NH}_{3}\right)_{2} \mathrm{I}_{2}\right]$. Reaction profiles monitored by both $1 \mathrm{D}$ ${ }^{1} \mathrm{H}$ and $2 \mathrm{D}\left[{ }^{1} \mathrm{H},{ }^{15} \mathrm{~N}\right]$ HSQC NMR spectroscopy indicate formation of a unique cross-link in the case of the unmodified tandem sheared G. A mismatch hexamer duplex $\mathrm{d}(\mathrm{GCGAGC})_{2}$ creating an interstrand head-to-tail G-N7Pt-G-N7 cis geometry complex. In contrast, the phosphorothioate counterpart duplex modified at the central GpA step (forming the stable duplex $\mathrm{d}\left(\mathrm{GCGsAG} \mathrm{C}^{5} \mathrm{C}_{2}\right.$ ) reacts with $\left[\mathrm{Pt}\left({ }^{15} \mathrm{NH}_{3}\right)_{2} \mathrm{I}_{2}\right]$ to form an intra-strand macrochelate adduct characterised by formation of a cross-link between phosphorothioate sulphur and $G^{5}-N 7$, readily formed as a result of the $\mathrm{B}_{\mathrm{II}}$ backbone geometry imposed by the interdigitized nature of the tandem sheared G.A mismatch structure of the duplex.

For the hairpin loop-forming mismatch sequence $d$ (CGCGTGCG), formation of stabilized duplex structures appears to take place when the central base step contains either phosphodiester or phosphorothioate but in the case of the latter, stabilization of a hairpin loop form is also consistent with the NMR data, suggesting formation of a $S, N$ macrochelate between phosphorothioate sulphur and $\mathrm{T}^{5}-N 3$.

Comparisons of these reactions with those of standard nucleic acid sequences possessing differing types of phosphodiester and phosphorothioate backbone geometries indicate that reaction profile is dependent on local geometrical considerations. Where such structures are present within a biological setting, these could act as valuable target sites. When combined with the notion of a therapeutic strategy involving composite drug delivery and activation using captive phosphorothioate oligonucleotides together with platinum(IV) prodrugs, the details presented in this work will serve as a useful point of reference for further ongoing investigations within this field.

\section{References}

[1] J. K. Vasir and M. S. V. Labhasetwar, "Targeted drug delivery in cancer therapy," Technology in Cancer Research and Treatment, vol. 4, no. 4, pp. 363-374, 2005.

[2] S. Dhar, F. X. Gu, R. Langer, O. C. Farokhza, and S. J. Lippard, "Targeted delivery of cisplatin to prostate cancer cells by aptamer functionalized Pt(IV) prodrug-PLGA - PEG 
nanoparticles," Proceedings of the National Academy of Sciences of the United States of America, vol. 105, no. 45, pp. 1735617361, 2008.

[3] M. Das, C. Mohanty, and S. K. Sahoo, "Ligand-based targeted therapy for cancer tissue," Expert Opinion on Drug Delivery, vol. 6, no. 3, pp. 285-304, 2009.

[4] S. Dhar, Z. Liu, J. Thomale, H. Dai, and S. J. Lippard, “Targeted single-wall carbon nanotube-mediated $\mathrm{Pt}(\mathrm{IV})$ prodrug delivery using folate as a homing device," Journal of the American Chemical Society, vol. 130, no. 34, pp. 11467-11476, 2008.

[5] N. J. Farrer, J. A. Woods, L. Salassa et al., "A potent transdiimine platinum anticancer complex photoactivated by visible light," Angewandte Chemie, vol. 49, no. 47, pp. 8905-8908, 2010.

[6] L. Cubo, A. M. Pizarro, A. G. Quiroga, L. Salassa, C. NavarroRanninger, and P. J. Sadler, "Photoactivation of trans diamine platinum complexes in aqueous solution and effect on reactivity towards nucleotides," Journal of Inorganic Biochemistry, vol. 104, no. 9, pp. 909-918, 2010.

[7] B. Lippert, Cisplatin: Chemistry and Biochemistry of a Leading Anticancer Drug, Wiley-VCH, Weinheim, Germany, 1999.

[8] T. Boulikas, A. Pantos, E. Bellis, and P. Christofis, "Designing platinum compounds in cancer: structures and mechanisms," Cancer Therapy, vol. 5, pp. 537-583, 2007.

[9] L. L. Slavin, E. H. Cox, and R. N. Bose, "Platinum(II)adenosine phosphothiorate complexes: kinetics of formation and phosphorus-31 NMR characterization studies," Bioconjugate Chemistry, vol. 5, no. 4, pp. 316-320, 1994.

[10] E. Volckova, L. P. Dudones, and R. N. Bose, "HPLC determination of binding of cisplatin to DNA in the presence of biological thiols: implications of dominant platinum-thiol binding to its anticancer action," Pharmaceutical Research, vol. 19, no. 2, pp. 124-131, 2002.

[11] S. Fakih, V. P. Munk, M. A. Shipman, P. D. S. Murdoch, J. A. Parkinson, and P. J. Sadler, "Novel adducts of the anticancer drug oxaliplatin with glutathione and redox reactions with glutathione disulfide," European Journal of Inorganic Chemistry, no. 6, pp. 1206-1214, 2003.

[12] P. D. S. Murdoch, N. A. Kratochwil, J. A. Parkinson, M. Patriarca, and P. J. Sadler, "A novel dinuclear diaminoplatinum(II) glutathione macrochelate," Angewandte Chemie, vol. 38, no. 19, pp. 2949-2951, 1999.

[13] N. A. Kratochwil, A. I. Ivanov, M. Patriarca, J. A. Parkinson, and P. J. Sadler, "Surprising reactions of iodo Pt(IV) and Pt(II) complexes with human albumin: implications for anticancer drug design," Journal of the American Chemical Society, vol. 121, pp. 8193-8203, 1999.

[14] N. A. Kratochwil, J. A. Parkinson, C. Sacht, P. D. S. Murdoch, T. Brown, and P. J. Sadler, " $\left[{ }^{1} \mathrm{H},{ }^{15} \mathrm{~N}\right]$ NMR studies of the platination of phosphorothioate nucleotides-monofunctional sulfur adducts versus macrochelation," European Journal of Inorganic Chemistry, no. 11, pp. 2743-2746, 2001.

[15] F. S. Mackay, J. A. Woods, P. Heringova et al., "A potent cytotoxic photoactivated platinum complex," Proceedings of the National Academy of Sciences of the United States of America, vol. 104, no. 52, pp. 20743-20748, 2007.

[16] J. Kasparkova, P. Heringova, V. Brabec, F. Mackay, and P. J. Sadler, "Photoactivated DNA modifications by platinum(IV) azide complex in cell free media," in Metal Ions in Biology and Medicine, P. Collery, Y. Maymard, T. Teophanides, L. Khassanova, and T. Collery, Eds., vol. 10, pp. 463-469, John Libbey Eurotext, Montrouge, France, 2008.
[17] P. J. Bednarski, F. S. Mackay, and P. J. Sadler, "Photoactivatable platinum complexes," Anti-Cancer Agents in Medicinal Chemistry, vol. 7, no. 1, pp. 75-93, 2007.

[18] T. L. Hwang and A. J. Shaka, "Water suppression that works," Journal of Magnetic Resonance, vol. 112, no. 2, pp. 275-279, 1995.

[19] B. Spingler, D. A. Whittington, and S. J. Lippard, "2.4 angstrom crystal structure of an oxaliplatin $1,2-\mathrm{d}(\mathrm{GpG})$ intrastrand Cross-link in a DNA dodecamer duplex," Inorganic Chemistry, vol. 40, no. 22, pp. 5596-5602, 2001.

[20] C. I. Diakos, B. A. Messerle, P. D. S. Murdoch et al., "Identification by NMR spectroscopy of the two stereoisomers of the platinum complex $\left[\mathrm{PtCl}_{2}(\mathrm{~S}\right.$-ahaz $\left.)\right](\mathrm{S}$-ahaz $=3(\mathrm{~S})$-Aminohexahydroazepine) Bound to a DNA 14-mer oligonucleotide. NMR evidence of structural alteration of a platinated A.T-rich 14-mer DNA duplex," Inorganic Chemistry, vol. 48, no. 7, pp. 3047-3056, 2009.

[21] J. A. Parkinson, Y. Chen, P. D. S. Murdoch et al., "Sequencedependent bending of DNA induced by cisplatin: NMR structures of an A . T-rich 14-mer duplex," Chemistry-A European Journal, vol. 6, no. 19, pp. 3636-3644, 2000.

[22] A. Gelasco and S. J. Lippard, "NMR solution structure of a DNA dodecamer duplex containing a cis- diammineplatinum(II) $\mathrm{d}(\mathrm{GpG})$ intrastrand cross-link, the major adduct of the anticancer drug cisplatin," Biochemistry, vol. 37, no. 26, pp. 9230-9239, 1998.

[23] F. Herman, J. Kozelka, V. Stoven et al., "A d(GpG)-platinated decanucleotide duplex is kinked-an extended NMR and molecular mechanics study," European Journal of Biochemistry, vol. 194, no. 1, pp. 119-133, 1990.

[24] P. M. Takahara, A. C. Rosenzweig, C. A. Frederick, and S. J. Lippard, "Crystal structure of double-stranded DNA containing the major adduct of the anticancer drug cisplatin," Nature, vol. 377, no. 6550, pp. 649-652, 1995.

[25] R. G. Pearson, "Hard and soft acids and bases," Journal of the American Chemical Society, vol. 85, no. 22, pp. 3533-3539, 1963.

[26] S. J. Berners-Price, K. J. Barnham, U. Frey, and P. J. Sadler, "Kinetic analysis of the stepwise platination of single- and double-stranded GG oligonucleotides with cisplatin and cis$\left[\mathrm{PtCl}\left(\mathrm{H}_{2} \mathrm{O}\right)\left(\mathrm{NH}_{3}\right)_{2}\right]^{+}$," Angewandte Chemie, vol. 35, no. 19, pp. 1283-1291, 1996.

[27] F. Reeder, Z. J. Guo, P. D. S. Murdoch et al., "Platination of a GG site on single-stranded and double-stranded forms of a 14-base oligonucleotide with diaqua cisplatin followed by NMR and HPLC. Influence of the platinum ligands and base sequence on 5'-G versus 3'-G platination selectivity," European Journal of Biochemistry, vol. 249, no. 2, pp. 370-382, 1997.

[28] L. J. Rinkel and J. I. Tinoco, "A proton NMR study of a DNA dumb-bell structure with hairpin loops of only two nucleotides: d(CACGTGTGTGCGTGCA)," Nucleic Acids Research, vol. 19, no. 13, pp. 3695-3700, 1991.

[29] L. P. M. Orbons, G. A. van der Marel, J. H. van Boom, and C. Altona, "An NMR study of the polymorphous behavior of the mismatched DNA octamer $\mathrm{d}\left(\mathrm{m}^{5} \mathrm{C}-\mathrm{G}-\mathrm{m}^{5} \mathrm{C}-\mathrm{G}-\mathrm{T}-\mathrm{G}-\mathrm{m}^{5} \mathrm{C}-\right.$ $\mathrm{G}$ ) in solution-the $\mathrm{B}, \mathrm{Z}$, and hairpin forms," Journal of Biomolecular Structure and Dynamics, vol. 4, no. 6, pp. 939963, 1987.

[30] M. P. Evstigneev, J. A. Parkinson, A. O. Lantushenko, V. V. Kostjukov, and V. I. Pahomov, "Hexamer oligonucleotide topology and assembly under solution phase NMR and theoretical modeling scrutiny," Biopolymers, vol. 93, no. 12, pp. 1023-1038, 2010. 
[31] H. L. Chen, P. Yang, C. X. Yuan, and X. H. Pu, "Study on the binding of base-mismatched oligonucleotide d(GCGAGC) by cobalt(III) complexes," European Journal of Inorganic Chemistry, no. 15, pp. 3141-3148, 2005.

[32] S. Limmer, "Mismatch base pairs in RNA," Progress in Nucleic Acid Research and Molecular Biology, vol. 57, pp. 1-39, 1997.

[33] N. Shankar, T. Xia, S. D. Kennedy, T. R. Krugh, D. H. Mathews, and D. H. Turner, "NMR reveals the absence of hydrogen bonding in adjacent UU and AG mismatches in an isolated internal loop from ribosomal RNA," Biochemistry, vol. 46, no. 44, pp. 12665-12678, 2007.

[34] H. A. Heus, S. S. Wijmenga, H. Hoppe, and C. W. Hilbers, "The detailed structure of tandem G.A mismatched base-pair motifs in RNA duplexes is context dependent," Journal of Molecular Biology, vol. 271, no. 1, pp. 147-158, 1997.

[35] S. Ebel, T. Brown, and A. N. Lane, "Thermodynamic stability and solution conformation of tandem $\mathrm{G} \cdot \mathrm{A}$ mismatches in RNA and RNA.DNA hybrid duplexes," European Journal of Biochemistry, vol. 220, no. 3, pp. 703-715, 1994.

[36] Y. G. Gao, H. Robinson, R. Sanishvili, A. Joachimiak, and A. H. J. Wang, "Structure and recognition of sheared tandem G.A base pairs associated with human centromere DNA sequence at atomic resolution," Biochemistry, vol. 38, no. 50, pp. 16452 16460, 1999.

[37] S.-H. Chou, K.-H. Chin, and A. H.-J. Wang, "Unusual DNA duplex and hairpin motifs," Nucleic Acids Research, vol. 31, no. 10, pp. 2461-2474, 2003.

[38] B. Hartmann, D. Piazzola, and R. Lavery, " $\mathrm{B}_{I}-\mathrm{B}_{I I}$ transitions in B-DNA," Nucleic Acids Research, vol. 21, no. 3, pp. 561-568, 1993.

[39] R. Narayanan and S. Akhtar, "Antisense therapy," Current Opinion in Oncology, vol. 8, no. 6, pp. 509-515, 1996.

[40] S. Agrawal and E. R. Kandimalla, "Antisense therapeutics: is it as simple as complementary base recognition?" Molecular Medicine Today, vol. 6, no. 72, p. 81, 2000.

[41] B. Roehr, "Fomivirsen approved for CMV retinitis," Journal of the International Association of Physicians in AIDS Care, vol. 4, no. 10, pp. 14-16, 1998.

[42] X. J. Tang and I. J. Dmochowski, "Synthesis of light-activated antisense oligodeoxynucleotide," Nature Protocols, vol. 1, no. 6, pp. 3041-3048, 2007.

[43] R. Huschka, J. Zuloaga, M. W. Knight, L. V. Brown, P. Nordlander, and N. J. Halas, "Light-induced release of DNA from gold nanoparticles: nanoshells and nanorods," Journal of the American Chemical Society, vol. 133, no. 31, pp. 12247-12255, 2011.

[44] A. Rotaru, J. Kovacs, and A. Mokhir, "Red light-activated phosphorothioate oligodeoxyribonucleotides," Bioorganic and Medicinal Chemistry Letters, vol. 18, no. 15, pp. 4336-4338, 2008. 


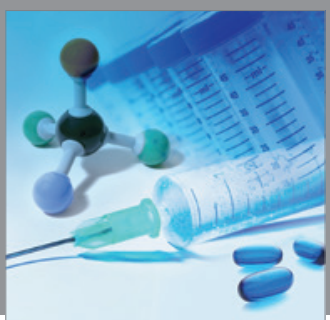

International Journal of

Medicinal Chemistry

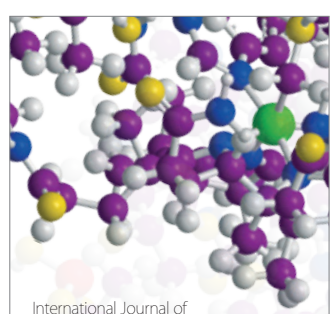

Carbohydrate Chemistry

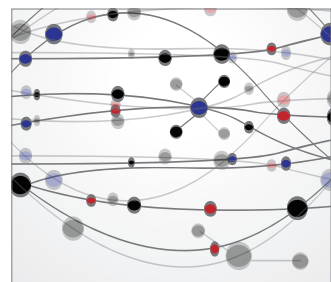

The Scientific World Journal
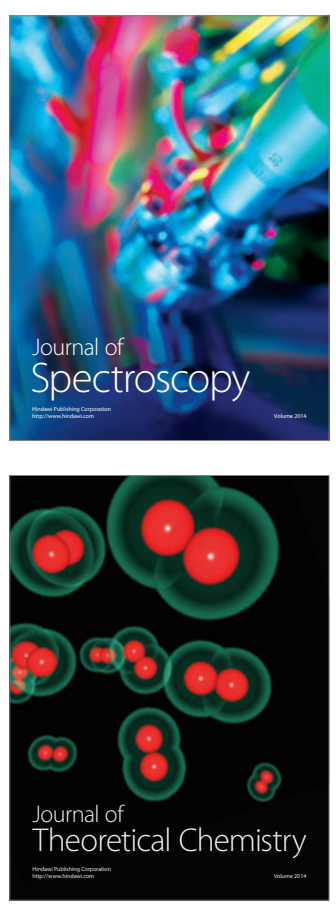
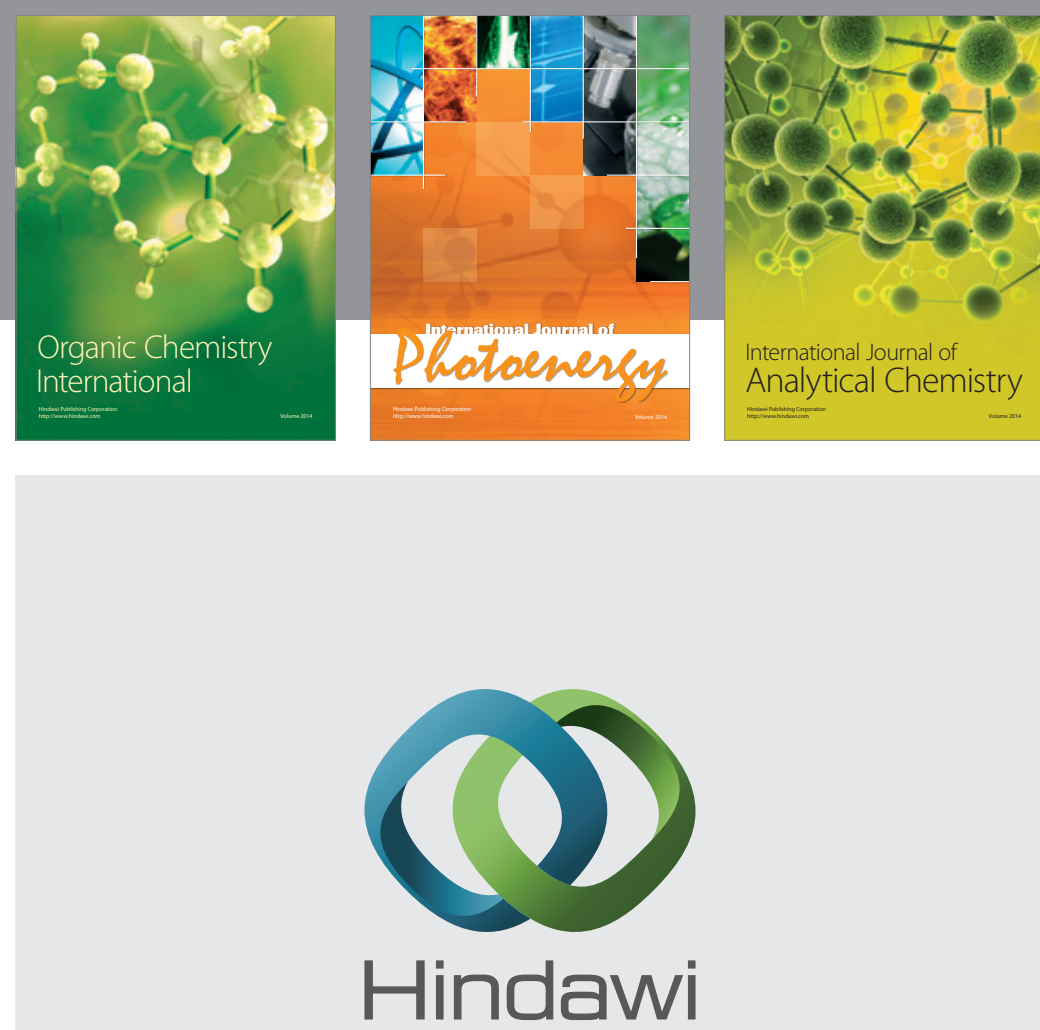

Submit your manuscripts at

http://www.hindawi.com
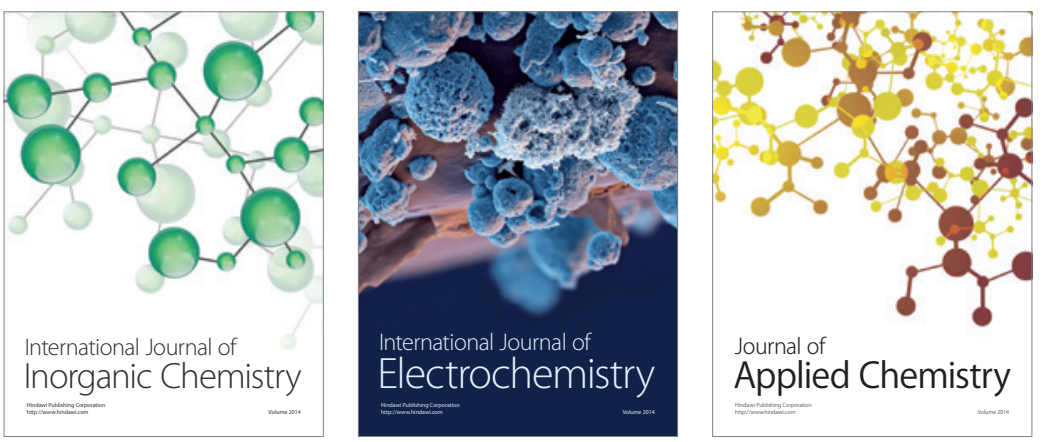

Journal of

Applied Chemistry
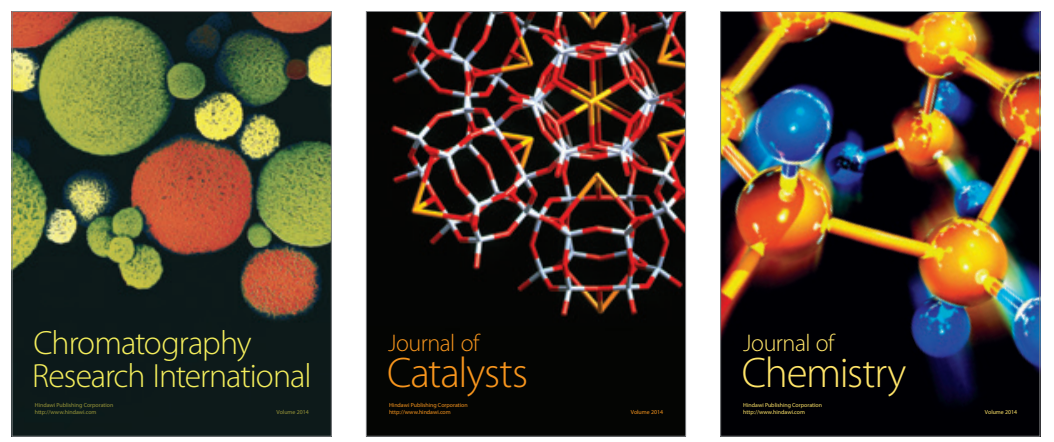
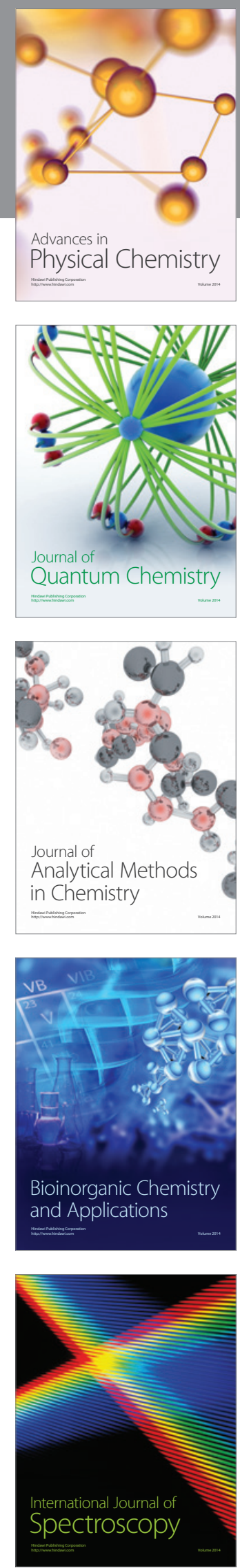